\title{
Cognitive and neuroplasticity mechanisms by which congenital or early blindness may confer a protective effect against schizophrenia
}

\author{
Steven M. Silverstein ${ }^{1,2}{ }^{*}$, Yushi Wang ${ }^{1}$ and Brian P. Keane ${ }^{1,2,3}$ \\ ${ }^{1}$ University Behavioral HealthCare, University of Medicine and Dentistry of New Jersey, Piscataway, NJ, USA \\ 2 Department of Psychiatry, University of Medicine and Dentistry of New Jersey, Robert Wood Johnson Medical School, Piscataway, NJ, USA \\ ${ }^{3}$ Rutgers University Center for Cognitive Science, Piscataway, NJ, USA
}

\section{Edited by:}

Michael Green, University of California Los Angeles, USA

Reviewed by:

Yue Chen, McLean Hospital, USA Jonathan K. Wynn, University of California Los Angeles, USA

${ }^{*}$ Correspondence:

Steven M. Silverstein, University Behavioral HealthCare, University of Medicine and Dentistry of New Jersey, 151 Centennial Avenue, Piscataway, NJ 08854, USA. e-mail: silvers1@umdnj.edu

\begin{abstract}
Several authors have noted that there are no reported cases of people with schizophrenia who were born blind or who developed blindness shortly after birth, suggesting that congenital or early (C/E) blindness may serve as a protective factor against schizophrenia. By what mechanisms might this effect operate? Here, we hypothesize that $\mathrm{C} / \mathrm{E}$ blindness offers protection by strengthening cognitive functions whose impairment characterizes schizophrenia, and by constraining cognitive processes that exhibit excessive flexibility in schizophrenia. After briefly summarizing evidence that schizophrenia is fundamentally a cognitive disorder, we review areas of perceptual and cognitive function that are both impaired in the illness and augmented in C/E blindness, as compared to healthy sighted individuals. We next discuss: (1) the role of neuroplasticity in driving these cognitive changes in C/E blindness; (2) evidence that $\mathrm{C} / \mathrm{E}$ blindness does not confer protective effects against other mental disorders; and (3) evidence that other forms of C/E sensory loss (e.g., deafness) do not reduce the risk of schizophrenia. We conclude by discussing implications of these data for designing cognitive training interventions to reduce schizophrenia-related cognitive impairment, and perhaps to reduce the likelihood of the development of the disorder itself.
\end{abstract}

Keywords: schizophrenia, blindness, perception, cognition, vision, vision disorders, plasticity

\section{INTRODUCTION}

Over the past 60 years, several authors (Chevigny and Braverman, 1950; Abely and Carton, 1967; Horrobin, 1979; Riscalla, 1980; Feierman, 1982; Sanders et al., 2003) have postulated that congenital or early $(\mathrm{C} / \mathrm{E})$ blindness may serve as a protective factor against the development of schizophrenia. Supporting data derive from several sources, including literature reviews, examination of cohorts of blind patients in psychiatric hospitals, and surveys of agencies that treat large numbers of blind people. The most recent of these Sanders et al. (2003) noted that across all past papers, there has not been even one reported case of a congenitally blind person who developed schizophrenia. While we identified one reported case of a blind "schizophrenic" child (Stewart and Sardo, 1965), the 6-year-old described in that paper had many symptoms of autism and no symptoms of psychosis, and would almost certainly be diagnosed with an autism-spectrum disorder using DSM-III (American Psychiatric Association, 1980) or later criteria. In contrast to the lack of cases of people with $\mathrm{C} / \mathrm{E}$ blindness who meet modern criteria for schizophrenia, reports do exist of people who develop both blindness and schizophrenia later in life (Checkley and Slade, 1979). We therefore hypothesize that it is the brain changes that occur secondary to C/E blindness - rather than blindness per se - that protect against schizophrenia. However, the mechanisms that confer this apparent protection have not yet been identified. In this paper, we advance the hypothesis that protection occurs by (1) strengthening the perceptual and cognitive functions whose impairment forms the essential nature of schizophrenia; and (2) constraining cognitive processes that are excessively neuroplastic in the illness.

In the discussion below, after briefly summarizing the position that schizophrenia is fundamentally a cognitive (i.e., informationprocessing) disorder, we review evidence that a cluster of perceptual and cognitive functions is at once markedly impaired in schizophrenia and significantly augmented in C/E blindness, compared to healthy sighted individuals (see Table 1). In subsequent sections, we explicate the role of neuroplasticity in driving these perceptual and cognitive differences, we provide evidence that C/E blindness does not confer protection against other mental disorders (e.g., depression, anorexia nervosa) and finally we argue that other forms of $\mathrm{C} / \mathrm{E}$ sensory loss (e.g., deafness) do not reduce the risk of schizophrenia. We conclude by noting the implications of these data for designing cognitive training interventions for patients and people at high risk for the disorder, and for developing interventions to prevent schizophrenia.

\section{SCHIZOPHRENIA AS A COGNITIVE DISORDER: KRAEPELIN AND DEMENTIA PRAECOX REVISITED}

Although the most obvious clinical features of schizophrenia include psychotic symptoms such as hallucinations, delusions, and bizarre behavior, it has long been thought that such symptoms 
Table 1 | Summary of cognitive and brain function enhancements $(+)$ and impairments $(-)$, compared to healthy sighted individuals, in C/E blindness and schizophrenia.

\begin{tabular}{|c|c|c|}
\hline Function & Blindness & Schizophrenia \\
\hline \multicolumn{3}{|l|}{ AUDITORY PERCEPTION } \\
\hline Localization & + & - \\
\hline Acuity & + & - \\
\hline Discrimination & + & - \\
\hline Comprehension & + & - \\
\hline Categorization & + & - \\
\hline Temporal resolution & + & - \\
\hline Latency of auditory ERPs & $+^{*}$ & $-{ }^{* *}$ \\
\hline \multicolumn{3}{|l|}{ AUDITORY ATTENTION } \\
\hline Preattentive processing (e.g., MMN) & + & - \\
\hline Selective attention & + & - \\
\hline Divided attention & + & - \\
\hline \multicolumn{3}{|l|}{ MEMORY } \\
\hline Working memory & + & - \\
\hline Short-term memory & + & - \\
\hline Long-term memory & + & - \\
\hline \multicolumn{3}{|l|}{ LANGUAGE } \\
\hline Lexical decision making & $+^{*}$ & $-{ }^{* *}$ \\
\hline Abstraction & - & + \\
\hline Conceptual inclusiveness & - & + \\
\hline Word inventions & - & + \\
\hline \multicolumn{3}{|c|}{ CONSTRUCTION OF SUBJECTIVE EXPERIENCE } \\
\hline Integration via serial processing & + & - \\
\hline Holistic processing & + & - \\
\hline Olfaction & + & - \\
\hline Motor control & + & - \\
\hline Body perception & + & - \\
\hline Plasticity & + & - \\
\hline
\end{tabular}

*Faster than normal.

* Slower than normal.

are secondary, compensatory, features of the disorder. In contrast, much evidence suggests that the core features of schizophrenia are cognitive in nature, involving disturbances in perception, attention, memory, learning, language, and context-based modulation of these processes as a function of expectations and action plans (Kraepelin, 1903; Bleuler, 1950; Weiss, 1989; Phillips and Silverstein, 2003; Nuechterlein et al., 2012; Tamminga, 2013; Khan, in press). In this way, schizophrenia can be viewed as similar to brain disorders such as Parkinson's disease dementia and dementia with Lewy bodies, in which psychotic symptoms can occur, but are often late-developing phenomena, and are not considered the defining features of the disorder (Ballard et al., 2001; Williams-Gray et al., 2006; Ffytche, 2007). A large body of research evidence now indicates that perceptual and cognitive impairments are found in nearly all people with schizophrenia, and occur with greater frequency than psychotic symptoms (Palmer et al., 2009). Significant cognitive impairment is also easily detectable in most schizophrenia patients even when psychotic symptoms are in remission (Altshuler et al., 2004). In addition: (1) low intelligence is a risk factor for schizophrenia; (2) cognitive decline and intellectual underperformance precede the onset of psychotic symptoms (and therefore the diagnosis) by many years; (3) decline in cognitive functioning continues after psychosis onset; and (4) this pattern of changes is not found in other major mental illnesses, even those that can include psychotic symptoms, such as bipolar disorder (Neumann et al., 1995; Schenkel and Silverstein, 2004; Khan, in press). Cognitive impairments in schizophrenia are also significantly correlated with level of functional disability (Green, 1996; Silverstein et al., 1998), and are therefore important treatment targets.

\section{DOMAINS OF PERCEPTUAL AND COGNITIVE FUNCTIONING THAT ARE STRENGTHENED BY C/E BLINDNESS AND IMPAIRED IN SCHIZOPHRENIA \\ AUDITORY PERCEPTION}

Compared to sighted people (and in some cases to late-blind people), C/E blind individuals are characterized by enhanced auditory acuity for pitch, better pitch discrimination, better pitch-timbre categorization (Wan et al., 2010), better speech discrimination (Hertrich et al., 2009), better sound localization, better temporal auditory resolution, better noise-embedded speech discrimination (Niemeyer and Starlinger, 1981; Muchnik et al., 1991), lower sound threshold for identification of pseudo-words (Rokem and Ahissar, 2009), shorter latencies for auditory event-related potentials (ERPs; Roder et al., 1996, 1999), and greater tolerance for short stimulus-onset asynchronies in an auditory backward masking task (Stevens and Weaver, 2005). C/E blindness is also associated with comprehension of ultra-fast synthetic speech at a rate of $\sim 25$ syllables per second, which is close to three times the rate at which non-blind individuals can comprehend such speech (Hertrich et al., 2009). In addition, C/E blind subjects have shown larger mismatch negativity (MMN) components of the ERP, suggesting a compensatory improvement in pre-attentional processes (Kujala et al., 1995). It has been demonstrated that these sensory and perceptual processing differences are due to enhanced basic perceptual skills, not to "higher order" functions such as attention, memory, language, or executive functions (reviewed in Cattaneo and Vecchi, 2011).

The above findings are in contrast to what has been observed in schizophrenia, in which, for example, patients are typically characterized by poor auditory acuity, precision, and discrimination (including in tone matching) (Javitt et al., 1997; Rabinowicz et al., 2000; Li et al., 2002; Rojas et al., 2007; Turetsky et al., 2009; Perrin et al., 2010; Kantrowitz et al., 2013), impairments in sound localization (Perrin et al., 2010), temporal resolution of sound (Foucher et al., 2007), auditory backward masking (Kallstrand et al., 2002), pre-attentional processing as indicated by the (smaller) MMN ERP component (Umbricht et al., 2003), and longer latency of post-attentional auditory ERPs (Ward et al., 1991; Sevik et al., 2011; Iyer et al., 2012). Individuals with schizophrenia also have abnormal processing of speech sounds (Ngan et al., 2003; Hirano et al., 2008), are worse than other groups at detecting speech embedded in noise, and are more likely than controls to identify non-speech sounds as speech (Vercammen et al., 2008). Importantly, it has been shown that these impairments in pitch processing in schizophrenia are not secondary to symptoms, medication, or poor attentional functioning (Rabinowicz et al., 2000). 
The impaired auditory functions noted above are not mere laboratory curiosities; they have important clinical and functional implications. For example, poor sound localization is thought to be associated with an externalization bias in which there is a reduced ability to recognize that the sound of one's own voice is coming from the self, as opposed to an external cause, which may contribute to delusional thinking (Johns et al., 2001; Ilankovic et al., 2011). At a more general level, perception has been conceptualized as an active, hypothesis-generating function that involves generating a model of the world, and then updating this model via coding of prediction error (i.e., the degree to which continued incoming sensory input does not conform to the current perceptual model of the world; Corlett et al., 2009; Clark, in press). It has been postulated that symptoms of schizophrenia, such as hallucinations and delusions may result from an impaired ability to detect inconsistencies between what would normally be expected (based on past experience) and incoming sensory information (Corlett et al., 2007, 2009; Clark, in press). Both faulty bottom-up processing and poor quality top-down feedback, as have been demonstrated in schizophrenia (Silverstein and Keane, 2009, 2011a,b), would degrade the quality of perceptual representations and the extent to which they are modified by context to most accurately reflect the nature of reality (Corlett et al., 2007, 2009; Clark, in press; Silverstein, in press). The result can be abnormal perceptions, hypersalience of normally ignored stimuli, and new and unusual beliefs to account for these changes in subjective experience - in short, an internal representation of the world that can deviate markedly from reality, and increasingly so over time (Clark, in press). In contrast, as C/E blindness is associated with enhanced sensory and perceptual processing, it can be seen how this would reduce the likelihood of the sort of prediction coding failures, and their sequelae, associated with schizophrenia. The auditory impairments in schizophrenia described above have also been shown to have other important consequences, which would not occur in people with $\mathrm{C} / \mathrm{E}$ blindness, such as problems decoding cues to emotion in speech (Leitman et al., 2011; Gold et al., 2012) and impaired semantic analysis (Leitman et al., 2007).

\section{AUDITORY ATTENTION}

Blindness has been associated with enhancements in several components of attention that are impaired in schizophrenia. For example, on reaction time tasks, blind subjects are superior to sighted individuals in responding to auditory and tactile cues (Collignon and De Volder, 2009). On tactile and auditory selective attention tasks involving spatial discrimination, blind people are more efficient than sighted subjects (Roder et al., 1996, 1999; Hotting and Roder, 2004; Collignon et al., 2006). Since these studies demonstrated that blind and sighted participants did not differ in sensory sensitivity on these tasks, these findings appear to reflect superior attentional capabilities (Cattaneo and Vecchi, 2011), although teasing apart attentional and perceptual deficits is often difficult. Blindness is also associated with superior performance on tasks of divided attention, such as dichotic listening (Hugdahl et al., 2004), and tasks requiring dividing attention across more than one sensory modality (Kujala et al., 1995). Again, such a pattern of performance contrasts sharply with what has been long been observed in schizophrenia, namely, severely impaired selective and divided auditory attention (Bleuler, 1950; Green et al., 1994; Heinrichs and Zakzanis, 1998; Bruder et al., 1999; Light and Braff, 2005a,b; Scholes and Martin-Iverson, 2010). In short, the improvements in sensory, perceptual, and attentional auditory functioning in $\mathrm{C} / \mathrm{E}$ blindness represent changes that appear to essentially eliminate the possibility of the development of the set of auditory impairments and their consequences that form an important component of schizophrenia.

\section{WORKING AND LONG-TERM MEMORY}

Compared to healthy, sighted individuals, $\mathrm{C} / \mathrm{E}$ blind individuals have superior working memory capacity, in terms of both the amount that can be processed, and the ability to recall the sequence in which information was presented (Hull and Mason, 1995; Amedi et al., 2003; Roder and Neville, 2003; Raz et al., 2007). The authors of a recent study that matched perceptual threshold of blind and sighted subjects concluded that superior short-term memory in $\mathrm{C} / \mathrm{E}$ blind people was due to enhancement of stimulus encoding (related to the processes reviewed above), rather than to differences in storage or recall processes (Rokem and Ahissar, 2009). In addition, it is thought that, in C/E blindness, primary reliance on controlled, sequential processes (i.e., via haptic and auditory perception) during navigation - as opposed to the more automatic and parallel processing normally afforded by vision leads to superior working memory abilities (Raz et al., 2007; Salillas et al., 2009; Cattaneo and Vecchi, 2011). C/E blind people have also demonstrated superior long-term memory compared to sighted controls (Bull et al., 1983; Roder et al., 2001). All of this is in stark contrast to schizophrenia, in which working memory (Silver et al., 2003; Conklin et al., 2005; Brahmbhatt et al., 2006; Horan et al., 2008; Silverstein et al., 2010) and long-term memory (Van Snellenberg, 2009) impairments are typically observed, along with problems in stimulus organization during encoding (Harvey et al., 1986; Brebion et al., 1997, 2004; Landgraf et al., 2011).

These data have important clinical implications. A critical function of WM is to integrate perceptual information with information stored in long-term memory, to allow for efficient learning, memory, and reasoning (Cattaneo and Vecchi, 2011). Enhanced $\mathrm{WM}$ abilities would thus facilitate these other processes, as is the case in C/E blindness (Cattaneo and Vecchi, 2011), whereas impairment would have the opposite effect, as is the case in schizophrenia (Tek et al., 2002). Thus, it can again be seen how C/E blindness could protect against development of the cognitive impairments that comprise the syndrome of schizophrenia.

\section{LANGUAGE}

Congenital or early blind children often experience language delays and abnormalities related to semantic, syntactic, and phonological processing (Perez-Pereira and Conti-Ramsden, 1999). One possible consequence of these is a reduction in the risk of developing disordered thought, which is commonly seen in schizophrenia. For example, many thought-disordered patients with schizophrenia have a tendency toward overabstraction and overinclusion in their thinking, as well as overly elaborated (and more easily primed) semantic networks (Siekmeier and Hoffman, 2002; Lerner et al., 2012). In addition, compared to healthy controls, individuals with schizophrenia more often use language in odd ways, including 
generating neologisms (i.e., novel words; Solovay et al., 1987; Kreher et al., 2008). In contrast, it has been shown that compared to sighted children, blind children are characterized by a lack of overgeneralization of concepts and categories, and a reduced number of word inventions (Andersen et al., 1984, 1993). It has also been shown that semantic networks in blind children are more dependent on language, and less dependent on sensory experience, than sighted children (Pring, 1988). This could be a protective factor against delusion formation secondary to altered sensory experience, as has been hypothesized to exist in schizophrenia (Maher, 1974; Uhlhaas and Mishara, 2007).

\section{OLFACTION}

Cuevas et al. (2009) demonstrated that congenitally blind males were better at discriminating odors, and at naming familiar odors, compared to sighted subjects. Other studies have reported mixed results, for example, demonstrating superior odor identification but not odor sensitivity (Wakefield et al., 2004). However, studies with mixed findings have grouped early blind and late-blind subjects together, and did not match groups on gender (women are typically better than men at olfaction tasks; Cattaneo and Vecchi, 2011). While more research is needed on this issue, evidence does suggest that people born blind may develop increased olfactory abilities (Kupers et al., 2011). This is in contrast to people with schizophrenia, in which olfactory impairments have been reported (Nguyen et al., 2010; Kamath et al., 2011). Although the functional consequences of olfactory impairment in schizophrenia are not well understood, such deficits could impair self-regulation, learning, attachment, and interpersonal functioning (see Sullivan, 2003). For example, the detection of maternal odor can promote attachment to the mother, reduce stress, and help normalize the sleep-wake cycle in infants (Goodin-Jones et al., 1997; Sullivan and Toubas, 1998). In addition, odor perception is important in forming bonds with peers in childhood (Sullivan, 2000). It is therefore interesting that risk for schizophrenia is associated with problems in maternal attachment (demonstrated at 3 days, 1 , and 6 years of age; Naslund et al., 1984; Persson-Blennow et al., 1984; McNeil and Kaij, 1987), increased stress reactivity (Myin-Germeys and van Os, 2007), and fewer peer relationships (Schenkel and Silverstein, 2004), as well as olfactory processing deficits (Brewer et al., 2003).

\section{CONSTRUCTION OF SUBJECTIVE EXPERIENCE}

In this section, we discuss: (1) differences between people who are $\mathrm{C} / \mathrm{E}$ blind and people with schizophrenia with regard to the relative importance of parallel versus serial data acquisition in the generation and quality of subjective experience; and (2) the role that preservation of a form of visual imagery in $\mathrm{C} / \mathrm{E}$ blindness may play in the integration of experience. As noted above, $\mathrm{C} / \mathrm{E}$ blind people rely to a much greater extent than sighted people on serial processing due to primary reliance on haptic and auditory processing, and lack of visual input. That is, due to the temporalsequential nature of data acquisition about objects in auditory and haptic perception, the relatively smaller amounts of information available at any one time in haptic perception compared to vision (Barber and Lederman, 1988; Amadeo and Speicher, 1995; Herssens, 2010), and the more rapidly changing nature of information flow in audition relative to vision (Shamma et al., 2011), formation of coherent mental representations in haptics and audition requires that information must be "built up" over time to a greater extent than in vision (Geenens, 1999). One result of this imposed learning style is that $\mathrm{C} / \mathrm{E}$ blind individuals develop abilities in sequential and controlled processing that may be superior to those of sighted people (Vecchi et al., 2004; Raz et al., 2007). In addition, as we argue below, compensatory processes involving working memory capacity, perceptual organization via controlled processing, multisensory integration, learning, and a preserved form of visual imagery lead to a rich, seemingly automatic, and non-fragmented flow of experience (see Cattaneo et al., 2008; Salillas et al., 2009 and above; Cattaneo and Vecchi, 2011). In contrast, in schizophrenia, impairments in working memory capacity, perceptual organization, and multisensory integration, which develop long after birth and for which there appear to be no compensation, contribute to an over-reliance on serial processing that is often inefficient, and that can lead to fragmented subjective experience (Chapman, 1966; Knight, 1984; Carr and Wale, 1986; Knight and Silverstein, 1998; Silverstein and Keane, 2011a). This is illustrated in the following quote from a person with schizophrenia: "Everything I see is split up. It's like a photograph that's torn in bits and put together again. If somebody moves or speaks, everything I see disappears quickly and I have to put it together again" (Chapman, 1966, p. 229).

Interesting examples of how blind individuals construct mental representations incrementally via haptic perception come from Helen Keller's (1908) book The World I Live In; her descriptions also illustrate how this process can be facilitated by prior knowledge and augmented with imagery. For example, she noted: "My fingers cannot, of course, get the impression of a large whole at a glance; but I feel the parts, and my mind puts them together" (p. 7). Similarly: "My hand has its share in this multiple knowledge, but it must never be forgotten that with the fingers I see only a very small portion of a surface, and that I must pass my hand continually over it before my touch grasps the whole. It is still more important, however, to remember that my imagination is not tethered to certain points, locations, and distances. It puts all the parts together simultaneously as if it saw or knew instead of feeling them." (pp. 28-29). It is true of course that vision also incrementally builds distal representations, viz, through saccades or shifts in attention (Ullman, 1984), but because this process is not limited by the speed of grasping and reaching, it plausibly occurs over a much shorter time scale, lessening the load on working memory. In short, while $\mathrm{C} / \mathrm{E}$ blindness is characterized by a greater than normal reliance on serial processing, compensatory processes lead to superior serial processing abilities and to integrated subjective experience.

In addition, we speculate that a preserved form of visual imagery is involved in the spatial integration abilities of $\mathrm{C} / \mathrm{E}$ blind people. A reasonable amount of evidence supports the presence of imagery in C/E blindness, including: (1) visual cortex areas are activated by input from other senses in blind and non-blind people (Amedi et al., 2001, 2002; Ortiz et al., 2011); (2) the occipital lobe helps generate mental representations even when there has been no prior visual input (Amedi et al., 2008); (3) after training with tactile stimulation, blind people reported visual qualia, and the extent of these reports were related to ERP activity in the lateral 
occipital complex (Ortiz et al., 2011); (4) C/E blind people have visual content in their dreams, and can draw it, and the extent of their dream imagery is negatively correlated with EEG alpha band power, just as it is in sighted individuals (Bertolo et al., 2003); (5) C/E blind people report visual imagery (Cornoldi et al., 1979; Zimler and Keenan, 1983), although this is reduced, and more verbally mediated, compared to sighted people (Cornoldi et al., 1979); (6) however, spatial representation is not completely verbally mediated in blind people; during the encoding and working memory maintenance phases of a haptic mental rotation task, both sighted and blind subjects demonstrated increased parietal activation (as demonstrated in ERP data; Roder et al., 1997); (7) spatial images are supramodal, in that they are not simply the sum of modality-specific inputs; (8) there are several characteristics of visual experience, such as size, contour, and edge information, shape and texture that can be perceived through touch, and blind people can generate visual representations of haptically explored objects (reviewed in Cattaneo et al., 2008; Cattaneo and Vecchi, 2011); (9) vision and haptics may share common representations (Aleman et al., 2001); and (10) both the dorsal and ventral pathways are thought to contain supramodal regions to code shape and location of objects, respectively, regardless of the nature of the sensory input (Pietrini et al., 2009). We suggest, based on the quotes cited above, and others in the literature, that these "visual" experiences and supramodal representations aid in integrating subjective experience in $\mathrm{C} / \mathrm{E}$ blindness. However, direct evidence for this claim has not yet been reported.

\section{C/E BLINDNESS IS PROTECTED FROM NEGATIVE DEVELOPMENTAL EFFECTS OF VISUAL PROCESSING IMPAIRMENTS}

Vision allows for the simultaneous perception of a great deal of information, and therefore for attention to be spread over many stimuli, or to be switched between stimuli. In schizophrenia, with its related sensory gating deficits, this can lead to the experience of being flooded with stimuli, and of stimuli being more intense than usual (Carr and Wale, 1986). In contrast, blindness is associated with touch as the primary method of exploring the environment. The nature of haptic perception is such that the person can only attend to the object currently being touched, and in this way attention cannot be involuntarily drawn to other objects (unless there are auditory or olfactory cues to other objects; Cattaneo and Vecchi, 2011).

Of course, we are not saying that vision is, by itself, a risk factor for schizophrenia. However, in combination with sensory gating, perceptual organization, and working memory impairments, visual processing, with its parallel inputs, may contribute to sensory flooding and subsequent disorganized cognition and behavior in schizophrenia. That is, visual impairment may be a risk factor for schizophrenia, not only in being reflective of abnormal neural development but also by being a cause of it. Conversely, C/E blindness may exert its protective effects against schizophrenia, in part, by preventing the possibility of abnormal visual input. Evidence consistent with this comes from several sources, including: (1) visual dysfunction in children of mothers with schizophrenia predicts the later development of schizophrenia (Schubert et al., 2005); (2) children (regardless of parental history) who later developed schizophrenia-spectrum disorders had significantly higher eye exam scale and strabismus scale scores compared to children who developed other non-psychotic psychopathology and children who did not develop a mental illness, while functioning in other sensory domains was far less impaired (Schiffman et al., 2006); and (3) the high specificity of visual abnormalities for predicting transition to schizophrenia among at-risk youth (Klosterkotter, 1992). In all of these cases, even if the presence of visual dysfunction is a reflection of the diathesis for schizophrenia rather than a primary cause of it, the continued state of abnormal visual input may lead to further perceptual and cognitive problems throughout development that increase the risk of developing the full-blown disorder.

Impaired visual functioning may also compromise multisensory integration, which, in turn, may lead to other cognitive deficits in schizophrenia. Efficient integration of different sensory inputs requires remapping these into an external spatial reference frame (Roder et al., 2007), which requires normal vision to properly develop (Collignon et al., 2009). However, in schizophrenia, there are multiple visual processing impairments (e.g., in gain control, perceptual organization, motion perception, etc.; Butler et al., 2008). Multisensory integration is also impaired in schizophrenia (Williams et al., 2010), and it is thought that deficits in visual processing contribute to this (Landgraf et al., 2012). In contrast, blind people appear to rely on somatotopic spatial coordinates as opposed to external, visual, coordinates (Roder et al., 2004). Therefore, in contrast to schizophrenia, in $\mathrm{C} / \mathrm{E}$ blindness, the primary sense used to create a reference frame for multisensory integration (i.e., touch) is associated with superior perceptual abilities compared to sighted people.

Blind people rely primarily on vestibular and somatosensory feedback for motor control. This leads to enhanced voluntary motor control and motor-kinesthetic processing (Deutschlander et al., 2009). In contrast, schizophrenia is associated with impaired motor control (Cortese et al., 2005; Putzhammer and Klein, 2006; Velasques et al., 2011), and it has been hypothesized that this could be related to passivity phenomena and the development of delusions of control (e.g., the belief that one is not the agent of one's own actions, and/or that an external entity is controlling one's thoughts and/or actions; Danckert et al., 2004). Abnormalities in movement have also been observed in people at high risk for schizophrenia (Mittal et al., 2008). Therefore, the enhanced development of motor control and kinesthetic processing in $\mathrm{C} / \mathrm{E}$ blindness can be viewed as protective against these schizophrenia-related symptom formation processes.

Finally, it has been recently proposed that visual processing disturbances in individuals at-risk for schizophrenia may contribute to the later development of the disorder by causing impairments in body perception, involving the senses of "ego boundaries," body ownership, body agency, and sense of self in space. These phenomena may then lead to problems in sense of identity, and in awareness of symptoms and insight into illness (Landgraf et al., 2012). Body ownership and agency can be measured experimentally with the "rubber hand illusion" (Ehrsson et al., 2004). In this paradigm, subjects have the experience that they are touching their own right hand with their left index finger, when in reality they are touching a rubber hand with their left index finger while the 
experimenter touches their right hand in a synchronized manner. This effect is enhanced in schizophrenia and is thought to reflect abnormal body perception including a reduction in sense of body ownership (Thakkar et al., 2011). In contrast, in people with $\mathrm{C} / \mathrm{E}$ blindness, the illusion is not experienced (Petkova et al., 2012). These results have been interpreted as indicating that $\mathrm{C} / \mathrm{E}$ blind people have a more veridical perception of self-touch, along with a less flexible and dynamic representation of their own body in space compared to sighted individuals (Petkova et al., 2012). We believe that this reduced flexibility in dynamic representation of the body, secondary to loss of vision, is a protective factor against the body perception abnormalities associated with schizophrenia that were noted above.

\section{NEUROPLASTICITY}

In this section we review evidence on how and where in the brain changes occur in response to $\mathrm{C} / \mathrm{E}$ blindness, and how these subserve the changes in cognitive functioning discussed above. There is a large literature on brain plasticity in blind people, including evidence for developmental crossmodal plasticity (see below) where areas of the occipital lobe are recruited for auditory and haptic perception (see Cattaneo and Vecchi, 2011 for a review), and also for olfaction (Kupers et al., 2011). Beyond this, however, other changes in developmental intramodal plasticity can occur which appear to result in perceptual and cognitive abilities that are opposite to those found in schizophrenia. For example, a magnetic source localization study (Elbert et al., 2002) indicated that dipoles associated with processing low- and high-frequency tones were more distant in blind people than in sighted subjects, suggesting an expansion of regions in the auditory cortex, supporting the superior pitch discrimination abilities noted above. Further evidence for intramodal plasticity in blind individuals is reduced hemodynamic responses to auditory stimulation in comparison to sighted subjects, which is thought to reflect increased efficiency in auditory signal processing within the temporal lobe, in light of the generally superior auditory processing abilities in this population (Stevens and Weaver, 2009). Evidence for changes regarding haptic perception comes from findings of reduced accuracy in identifying which finger is touched during a sensory threshold task (Sterr et al., 1998, 2003), within the context of overall superior tactile perception (Wong et al., 2011). These data suggested altered cortical representations for touch in the sense that the cortical representations of individual fingers are "fused" together due to their simultaneous use during Braille reading. Moreover, these data are strongest for the hand used to read Braille, and do not generalize to other body parts that are not used for reading, such as lips. Of note, the "holistic" processing of Braille letter patterns and reduced precision of individual finger-level input is in contrast to what is often observed in the visual processing of people with schizophrenia, where processing of holistic visual patterns is impaired, sometimes with enhanced processing of individual visual details (reviewed in Uhlhaas and Silverstein, 2005; Silverstein and Keane, 2011a).

Developmental crossmodal plasticity can lead to superior performance compared to sighted subjects, and there are several interesting instances of this relevant to schizophrenia. For example, somatosensory and auditory ERP data from oddball and MMN tasks (which involve detection of a deviation from a sequential pattern in an attended or unattended sequence of stimuli, respectively), indicate normal ERP amplitude, with more activity over the occipital cortex in blind subjects, and enhanced pre-attentional processing in blind compared to sighted subjects (Kujala et al., 1995; Roder et al., 1996). This is in marked contrast to abnormal ERP amplitudes during oddball and MMN tasks in people with schizophrenia (e.g., Kayser et al., 2001) as noted above. Aside from developmental neuroplasticity, other ERP data from oddball tasks in people with schizophrenia suggested reduced short-term neuroplasticity. For example, when people with schizophrenia are presented with a high-frequency sequence of individual auditory stimulations, their ERP signatures reveal abnormally reduced long-term potentiation (Mears and Spencer, 2012). In contrast, short-term neuroplasticity, at least involving the occipital cortex, may be greater in people with $\mathrm{C} / \mathrm{E}$ blindness (De Volder et al., 1999).

A major focus of research on visual processing in schizophrenia is impaired functioning in the dorsal and ventral visual streams. Therefore, we briefly summarize evidence that, in contrast to what is observed in schizophrenia, functioning in these pathways is intact in C/E blindness, despite the absence of visual input. Much evidence suggests that the dorsal stream is specialized for determining where an object is and for guiding action, whereas the ventral stream is specialized for analyzing form and color for determining what an object is (Goodale, 1993; Goodale et al., 2005). Many studies indicate impaired functioning of both of these streams in schizophrenia (e.g., King et al., 2008; Silverstein et al., 2009; Sehatpour et al., 2010; Lalor et al., 2012; Plomp et al., 2012). Surprisingly, these pathways appear to subserve similar functions in blind people as they do in psychiatrically healthy sighted people, suggesting that they can develop even in the absence of visual experience, and therefore that their representations are supramodal (Cattaneo and Vecchi, 2011; Ptito et al., 2012). For example, during spatial imagery tasks using auditory or tactile stimuli, early blind and sighted individuals demonstrated similar dorsal stream and frontal eye field activation, as assessed via PET or fMRI (Vanlierde et al., 2003; Garg et al., 2007; Bonino et al., 2008). In addition, dorsal areas devoted to processing motion information in sighted people (e.g., V5/MT) are employed in blind people in response to tactile and auditory motion cues (e.g., Ptito et al., 2009; Bedny et al., 2010; Matteau et al., 2010). These areas are notably underactivated during perception of visual motion in schizophrenia, in the context of impaired motion perception (Chen, 2011). In the ventral stream, blind subjects demonstrated similar activation during tactile object perception to that shown by sighted subjects during visual and haptic exploration of the same objects (Pietrini et al., 2004; Ptito et al., 2012).

It should be noted that while occipital lobe activity can occur in sighted subjects during tactile and auditory processing tasks, this has been found to be due to visual imagery (Sathian, 2005), which activates early visual cortex areas in a retinotopic fashion (Slotnick et al., 2005), and to calibration of head-centered sound localization (Zimmer et al., 2004). In contrast, occipital cortex activity in $\mathrm{C} / \mathrm{E}$ blind subjects appears to support actual non-visual stimulus processing, and to represent a true crossmodal reorganization (see Roder et al., 1997; Cattaneo and Vecchi, 2011 for a 
review). Consistent with this, transcranial magnetic stimulation (TMS), applied to the occipital cortex, disrupts Braille reading ability in blind individuals, but not in sighted individuals, whereas the reverse is true when TMS is applied over the somatosensory cortex in the parietal lobe (Cohen et al., 1997). Similarly, TMS over the occipital cortex induces tactile sensations in blind readers' fingers, but only phosphene perception for sighted subjects (Ptito et al., 2008).

As noted above, schizophrenia patients have demonstrated olfactory deficits in several studies, while $\mathrm{C} / \mathrm{E}$ blind individuals have demonstrated superior olfactory abilities. A recent study, comparing congenitally blind subjects to blindfolded sighted controls, demonstrated that this is due to enhanced processing in areas normally dedicated to olfaction (e.g., amygdala, hippocampus) and in multiple regions of the occipital cortex (Kupers et al., 2011). This is further evidence of both the supramodal nature of representations in the $\mathrm{C} / \mathrm{E}$ visually deprived occipital lobe, and also of crossmodal plasticity in C/E blindness.

In addition to subserving enhanced non-visual sensory processing, fMRI data indicate that the occipital lobe in $\mathrm{C} / \mathrm{E}$ blind individuals also supports syntactic and semantic (more so than phonological) aspects of language processing (Roder et al., 2002; Burton et al., 2003), as well as verbal memory, episodic memory, and verbal fluency (Amedi et al., 2003; Raz et al., 2005), all of these being processes that are impaired in schizophrenia (Tendolkar et al., 2002; Fisher et al., 2009; Costafreda et al., 2011). For example, in addition to occipital lobe activation during memory retrieval, and a correlation between occipital activation and episodic memory in blind but not sighted subjects (Raz et al., 2005), repetitive transcranial magnetic stimulation (rTMS) over the occipital lobe impaired performance in a verb generation task for blind but not sighted subjects (Amedi et al., 2004).

Another consequence of blindness may be increased communication between brain regions. Several studies have demonstrated increased effective connectivity between the occipital lobe and temporal and prefrontal regions in early blind individuals (e.g., Noppeney et al., 2003; Leclerc et al., 2005). This is in contrast to schizophrenia, where reduced connectivity is typically found (e.g., Kim et al., 2008; Dima et al., 2009, 2010), including between occipital and temporal and frontal regions (Rigucci et al., 2012).

Finally, Sanders et al. (2003), based on evidence of visual cortex plasticity in dark-reared animals (Chen and Bear, 2007; Chen et al., 2007), proposed that an effect of early blindness is increased NMDA-receptor activity (although accompanied by reduced numbers of receptors) in visual cortex, and in regions with which this has many connections, primarily the anterior cingulate cortex (ACC), which is involved in resolving response competition and context sensitivity, two cognitive domains that are impaired in schizophrenia (Cohen and Servan-Schreiber, 1992; Dolan et al., 1995; Phillips and Silverstein, 2003). Moreover, schizophrenia has been characterized by NMDA-receptor hypofunction (Phillips and Silverstein, 2003), and, in numerous studies, by ACC hypoactivation (Dolan et al., 1995). The consequences of NMDAreceptor hypofunction in schizophrenia have been hypothesized to include impairments in sensory gating, perception, working memory, learning, and the full range of positive and negative symptoms (Phillips and Silverstein, 2003; Coyle, 2012). Therefore, an increase in NMDA-receptor activity in C/E blindness could have widespread positive effects on cognition, and protective effects against symptoms.

In short, there are several ways in which the neuroplasticity that results from $\mathrm{C} / \mathrm{E}$ blindness results in changes that are opposite to those observed in schizophrenia, and that may represent protective effects. Specifically, the evidence reviewed above suggests that, in C/E blindness: (1) despite the loss of visual input, cortical reorganization during early development leads to accurate form and space perception (via auditory and tactile processing) which is supported by brain areas that function abnormally in schizophrenia (e.g., dorsal and ventral visual streams); (2) this developmental plasticity also leads to use of occipital areas for functions such as preattentive processing (e.g., as reflected in the MMN), language, memory, and olfaction - all of which are impaired in schizophrenia - which may underlie the superior functioning in those areas in $\mathrm{C} / \mathrm{E}$ blindness reviewed above; and (3) in addition to these sequelae of developmental plasticity in $\mathrm{C} / \mathrm{E}$ blindness, there is also evidence of normal later-onset plasticity, which may in part reflect prolonged plasticity of the occipital cortex in C/E blindness (De Volder et al., 1999), and which is the basis for the success of sensory substitution devices (Ward and Meijer, 2010). In contrast, later-onset plasticity has been shown to be reduced in schizophrenia in several domains (Fitzgerald et al., 2004; Oxley et al., 2004; Daskalakis et al., 2008; Hasan et al., 2011, 2012; Mears and Spencer, 2012).

\section{CONGENITAL OR EARLY BLINDNESS IS NOT PROTECTIVE AGAINST MENTAL DISORDERS IN GENERAL}

While C/E blindness may protect against schizophrenia, they do not protect against mental illness in general. A range of mental and behavioral disorders has been reported in blind people. For example, anxiety levels have been reported to be higher in congenitally blind than sighted adolescents (Bolat et al., 2011), and autistic symptoms and autism are common in blind children (Keeler, 1958; Wing, 1969; Chess, 1971; Chase, 1972; Fraiberg, 1977; Rogers and Newhart-Larson, 1989; Brown et al., 1997; Ek et al., 1998; Carvill, 2001). Sharp (1993) reported a case of anorexia nervosa and depression in a woman blind since the age of 9 months. A recent case study (Kocourkova et al., 2011) described a case of an adolescent patient, blind from early childhood, who showed symptoms of anorexia, depression, suicidal behavior, and self-harming. A conclusion in this report was that body image is a mental construct that is not dependent on sensory perception. Finally, Musial et al. (2007) reported a case of arachnophobia in a congenitally blind person, suggesting that visual cues are not necessary for the development of phobic disorders.

\section{CONGENITAL DEAFBLINDNESS IS NOT PROTECTIVE AGAINST SCHIZOPHRENIA}

Protective effects of blindness may not exist if other forms of severe sensory loss are present. For example, congenital deafblindness is associated with elevated rates of psychosis, as well as mental retardation (Dammeyer, 2011). Also, children with Usher syndrome, in which people are typically deaf from birth and then develop retinitis pigmentosa leading to blindness in childhood, has been associated with psychotic symptoms and schizophrenia 
(Dammeyer, 2012). The reason why adding deafness to blindness removes the apparent effect of the latter against schizophrenia is not clear at present. One possibility is that blindness by itself presents a surmountable challenge to cope with the environment and thereby fosters compensatory sensory, perceptual, and cognitive changes that lead to a surprisingly high level of functioning. Deafblindness, on the other hand, may so seriously restrict the opportunity for environmental interaction that it also stunts the development of cognitively based coping strategies. For example, congenital deafblindness typically leads to significant delays in achieving several cognitive milestones, and to profound impairments in speed of processing, the ability to integrate disparate items of information, attention, communication, and the capacity for symbolic understanding and expression (Geenens, 1999; Bruce, 2005; Shamma et al., 2011). It is worth noting here that although $\mathrm{C} / \mathrm{E}$ blindness and $\mathrm{C} / \mathrm{E}$ deafblindness are both relatively rare, there are no published cases of the former being comorbid with schizophrenia, whereas there are many reported cases of this comorbidity with the latter.

\section{SENSORY LOSS IN GENERAL DOES NOT PROTECT AGAINST SCHIZOPHRENIA}

Another important consideration is that sensory loss per se does not protect against schizophrenia. For example, deafness occurs in schizophrenia at as high a rate as in the general population (Kitson and Fry, 1990), and congenital deafness is a risk factor for the development of psychotic symptoms (Thewissen et al., 2005; Atkinson, 2006), including, interestingly, higher rates of visual and somatic hallucinations than are found in the non-deaf people with schizophrenia (Cutting, 1985), which often co-occur with reports of hearing voices (Du Feu and McKenna, 1999). And, while deafness may be associated with compensatory cognitive changes (see Bross, 1979; Dye and Bavelier, 2010; e.g., heightened attention to visual peripheral cues in people who use sign language; Proksch and Bavelier, 2002), these appear to not protect against schizophrenia, although they may lead to subtle differences in profiles of cognitive impairment between deaf and hearing people with schizophrenia (Horton and Silverstein, 2007, 2011). Moreover, in some cases, compensatory changes may not develop until adulthood (Rettenbach et al., 1999).

\section{MEDIATING BIOLOGICAL VARIABLES}

The hypothesized protective effects of blindness on schizophrenia may be mediated by other factors. For example, Horrobin (1979) proposed that abnormal pineal gland function and resulting prostaglandin activity are etiological factors in schizophrenia. This is supported by evidence of increased inflammation and reduced melatonin levels in schizophrenia patients (Anderson and Maes, 2012; Muller et al., 2012). Conversely, blind individuals have elevated melatonin levels (Bellastella et al., 1995), which has been shown to attenuate cognitive impairments (Peck et al., 2004) and reduce inflammation (Cuzzocrea et al., 1999; Sharma et al., 2012). Another potential mechanism involves cortical thickness and pruning. Schizophrenia is typically characterized by cortical thinning (Cobia et al., 2012), and it has been hypothesized that excessive neuronal pruning takes place during adolescence (Boksa, 2012). In contrast, the visual cortex of $\mathrm{C} / \mathrm{E}$ blind people - which as noted above is involved in multiple perceptual and cognitive processes - is thicker than in sighted people, and is thought to be characterized by a less than normal amount of pruning, due to deprivation of visual experience (Jiang et al., 2009). A consequence of this thickening is that, even if genes related to schizophrenia cause excessive pruning in someone with $\mathrm{C} / \mathrm{E}$ blindness, the remaining number of neurons may still be greater than normal in some areas. This, in combination with the cortical reorganization noted above, leading to occipital regions being used for non-visual cognitive processes, may protect blind people against crossing the threshold needed for psychotic symptoms to emerge (i.e., an adequate number of neurons devoted to specific types of processing may be present even if pruning is excessive).

\section{CONCLUSION}

This paper builds on previous reports of a lack of schizophrenia in people with $\mathrm{C} / \mathrm{E}$ blindness by advancing the hypothesis that the latter alters cognition and fosters neuroplasticity in ways that confer protective effects against schizophrenia. The reviewed evidence indicates that: (1) schizophrenia is primarily a cognitive disorder; (2) many of the cognitive functions that are impaired in schizophrenia are enhanced among the C/E blind; (3) C/E blindness involves reduced flexibility in language and in dynamic representation of the body, and these reductions may protect against thought disorder and alterations in experience of the self, respectively; (4) the mechanisms noted in 2 and 3 above are significantly less affected if the onset of blindness is after the first few months of life; (5) other forms of C/E sensory loss do not protect against schizophrenia; and (6) C/E blindness does not protect against other disorders, suggesting that there is a special link between schizophrenia and visual processing.

Of course, schizophrenia is characterized by cognitive impairments in addition to those described here, such as in executive functioning, that are thought to rely heavily on functioning of the dorsolateral prefrontal cortex (DLPFC). There appears to be almost no research comparing blind (congenital or acquired) and sighted people on these functions, however, and so whether blindness confers any protective effects on them remains an open question. Note, however, that the DLPFC does not fully develop until late adolescence or early adulthood. In contrast, cognitive and academic decline, and interpersonal dysfunction, typically begin in late childhood or early adolescence in people who go on to develop schizophrenia, and this age range corresponds to the time frame in which the visual system in humans is most plastic (i.e., until 1416 years of age; Cohen et al., 1999). This suggests that the protective sequelae of $\mathrm{C} / \mathrm{E}$ blindness involve changes in more basic sensory, perceptual, and cognitive (i.e., non-executive) functions.

While the idea of one abnormal condition having a protective effect against another condition may seem unusual, it is not unknown. For example, several studies have now replicated the finding that schizophrenia appears to have an inverse relationship with rheumatoid arthritis (RA), with some estimates putting the risk for RA among schizophrenia patients at $30 \%$ that of control counterparts (Eaton et al., 1992; Mors et al., 1999; Oken and Schulzer, 1999). Conversely, there may also be a reduced risk for developing schizophrenia among individuals with RA (Gorwood et al., 2004). This is especially low considering smoking 
is a risk factor for developing RA (Stolt et al., 2003) and that a disproportionally large percentage $(60-90 \%)$ of individuals with schizophrenia smoke (Dervaux and Laqueille, 2008). As noted, we hypothesize that the cognitive benefits conferred by $\mathrm{C} / \mathrm{E}$ blindness act as a prophylactic for schizophrenia but not other mental disorders. This hypothesis, if confirmed, has implications for determining when cognitive training should occur for people with, or at-risk for, schizophrenia, and for the nature of such training. It also has implications for whether insights from $\mathrm{C} / \mathrm{E}$ blindness can be used to design interventions to prevent schizophrenia. Each of these issues will be addressed in turn below.

Evidence from animal studies indicates that prevention of schizophrenia-related cognitive impairment can be achieved by early cognitive training. For example, in one study, rats received a ventral hippocampus lesion that induces a spatial working memory deficit similar to that found among schizophrenia patients. It was found that among animals that had been provided with pre-lesioning cognitive training, the typical post-lesion working memory deficit did not arise (Lee et al., 2012). While similar preventive data do not exist in humans, a recent study of cognitive remediation in first-episode schizophrenia demonstrated that it significantly slowed the typical gray matter loss associated with the first years after an initial psychotic episode (Eack et al., 2010). Therefore, it is reasonable to study whether the long-term effects of cognitive training in people at high risk for the disorder could be at least as strong, if not stronger, than effects of cognitive training introduced after a diagnosis of schizophrenia is made, given that the effects are occurring in the context of a healthier and younger brain.

But when should training occur? Evidence indicates that intervening when people first begin to show psychotic symptoms or functional decline (i.e., in the "ultra high-risk" state) can delay, but does not prevent, schizophrenia (Yung and Nelson, 2011). Therefore, it has recently been proposed that intervening at a "pluripotent risk stage" - the time of the earliest emergence of behavioral and cognitive difficulties (typically 9-13 years of age) that are non-specific as to final diagnosis - would be more effective (Agius et al., 2010; McGorry, 2010; McGorry et al., 2010; Morgan et al., in press). Whether or not such a strategy can prevent schizophrenia, it may be an ideal time for intensive cognitive training, in terms of affording protection against later and severe schizophrenia-related cognitive impairment. Of course, even earlier training could be effective, but the feasibility of identifying people at high risk for mental illness at younger than 9-years old has not been well-established, except in cases where an identical twin or first-degree relative has the disorder.

What sort of training would be effective? Based on the evidence reviewed above, we suggest that cognitive training in young people at-risk for schizophrenia should be comprehensive in nature, and should focus to a greater degree than it has in the past on sensory and perceptual functioning. For example, in addition to a focus on improving aspects of attention, it should focus on improving sensory tuning and the accuracy of sensory representations, perceptual organization, multisensory integration, and controlled processing including integration of bottom-up sensory data with stored information (see Heller quotes above, and Hemsley, 1996). Some interventions have already demonstrated success in improving functioning in these specific areas in humans (Temple et al., 2003; Mahncke et al., 2006; Genevsky et al., 2010) and animals (Polley et al., 2006; Zhou et al., 2011). In addition, although schizophrenia patients often demonstrate reduced plasticity, it is not absent, and capacity for perceptual and cognitive change has been demonstrated (Fisher et al., 2009, 2010; Silverstein and Keane, 2009) both in and outside the context of specific interventions. Therefore, it is possible that even greater plasticity can be harnessed earlier in the developmental course of the illness, before psychotic symptoms emerge and near the onset of, or prior to, cognitive and functional decline. In addition, it has already been demonstrated in schizophrenia that improving auditory precision by repeated practicing of tone discrimination leads to improvements in auditory and (more interestingly) higher level cognitive functions (e.g., verbal learning and memory; Adcock et al., 2009; Fisher et al., 2009). Therefore, broader improvements (beyond the trained task) may occur in at-risk youth with similar practice.

An additional strategy for people at-risk for schizophrenia involves increasing reliance on non-visual sensory modalities to enhance their functioning. Already it has been shown in people with established schizophrenia, for example, that steady-state auditory responses, which are typically abnormally reduced and associated with an increase in broadband noise, can be significantly improved, and to a greater degree than occurs in healthy people, by closing the eyes during task performance (GriskovaBulanova et al., 2012). Fostering cognitive reserve, and trying to prevent schizophrenia, or at least minimize later illness-related cognitive impairment, by strengthening capacity and efficiency in non-visual domains is an as yet untested strategy. However, the goal of creating a schizophrenia-specific, acquired cognitive reserve, in a manner guided by compensatory changes observed in $\mathrm{C} / \mathrm{E}$ blindness, would appear to be a reasonable and promising direction to pursue, given that premorbid cognitive reserve predicts later cognitive functioning in normal aging (Steffener and Stern, 2012), neurodegenerative disorders (Koerts et al., 2012; Stern, 2012), and schizophrenia (de La Serna et al., 2013).

Can an understanding of cognition and neuroplasticity in $\mathrm{C} / \mathrm{E}$ blindness be used to reduce the likelihood of schizophrenia? At first glance, the answer seems to be "no" since: (1) only $\mathrm{C} / \mathrm{E}$ blindness (but not blindness acquired after the first few months of life) is associated with a protective effect; (2) it is difficult to identify most people who will develop schizophrenia during the first year of life; (3) it is not clear what type of training could be given to people less than 1-year old, given limited attention span and undeveloped verbal abilities; and (4) the presence of vision is likely to reduce the extent of developmental neuroplasticity. However, the ultimate answer to this question may not be this simple. For example, much remains to be learned about biological and computational changes associated with $\mathrm{C} / \mathrm{E}$, and later-developing, blindness, and so further investigation into these issues may reveal clues for intervention development. Also, it is not known beyond what age fostering neuroplasticity and cognitive enhancement might no longer be able to prevent schizophrenia, but only reduce schizophrenia-related cognitive impairment. Third, since it is not $\mathrm{C} / \mathrm{E}$ blindness per se, 
but rather, the corresponding brain and cognitive changes that are protective against schizophrenia, it is possible that methods other than naturally occurring $\mathrm{C} / \mathrm{E}$ blindness can confer protective effects. For example, an open question is the extent to which particularly intensive sensory-perceptual-cognitive interventions delivered to at-risk youth past the first year of life can create some of the protective changes associated with naturally occurring $\mathrm{C} / \mathrm{E}$ blindness.

\section{REFERENCES}

Abely, P., and Carton, C. (1967). [The man of night and the man of silence. Prologue to an attempted comparative psychopathologic and psychiatric study of the blind and deaf]. Ann. Med. Psychol. (Paris) 125, 111-125.

Adcock, R. A., Dale, C., Fisher, M., Aldebot, S., Genevsky, A., Simpson, G. V., et al. (2009). When topdown meets bottom-up: auditory training enhances verbal memory in schizophrenia. Schizophr. Bull. 35, 1132-1141.

Agius, M., Goh, C., Ulhaq, S., and McGorry, P. (2010). The staging model in schizophrenia, and its clinical implications. Psychiatr. Danub. 22, 211-220.

Aleman, A., Van Lee, L., Mantione, M. H., Verkoijen, I. G., and De Haan, E. H. (2001). Visual imagery without visual experience: evidence from congenitally totally blind people. Neuroreport 12, 2601-2604.

Altshuler, L. L., Ventura, J., Van Gorp, W. G., Green, M. F., Theberge, D. C., and Mintz, J. (2004). Neurocognitive function in clinically stable men with bipolar I disorder or schizophrenia and normal control subjects. Biol. Psychiatry 56, 560-569.

Amadeo, D., and Speicher, K. (1995). Essential environmental and spatial concerns for the congenitally visually impaired. J. Plan. Educ. Res. 14, 113-122.

Amedi, A., Floel, A., Knecht, S., Zohary, E., and Cohen, L. G. (2004). Transcranial magnetic stimulation of the occipital pole interferes with verbal processing in blind subjects. Nat. Neurosci. 7, 1266-1270.

Amedi, A., Jacobson, G., Hendler, T., Malach, R., and Zohary, E. (2002). Convergence of visual and tactile shape processing in the human lateral occipital complex. Cereb. Cortex 12, 1202-1212.

Amedi, A., Malach, R., Hendler, T., Peled, S., and Zohary, E. (2001). Visuo-haptic object-related activation in the ventral visual pathway. Nat. Neurosci. 4, 324-330.

Amedi, A., Merabet, L. B., Camprodon, J., Bermpohl, F., Fox, S., Ronen, I., et al. (2008). Neural and behavioral correlates of drawing in an early blind painter: a case study. Brain Res. 1242, 252-262.

Amedi, A., Raz, N., Pianka, P., Malach, R., and Zohary, E. (2003). Early 'visual' cortex activation correlates with superior verbal memory performance in the blind. Nat. Neurosci. 6, 758-766.

American Psychiatric Association. (1980). Diagnostic and Statistical Manual of Mental Disorders, 3rd Edn. Washington: American Psychiatric Association.

Andersen, E. S., Dunlea, A., and Kekelis, L. S. (1984). Blind children's language: resolving some differences. J. Child Lang. 11, 645-664.

Andersen, E. S., Dunlea, A., and Kekelis, L. S. (1993). The impact of input: language acquisition in the visually impaired. First Lang. 13, 23-49.

Anderson, G., and Maes, M. (2012). Melatonin: an overlooked factor in schizophrenia and in the inhibition of anti-psychotic side effects. Metab. Brain Dis. 27, 113-119.

Atkinson, J. R. (2006). The perceptual characteristics of voice-hallucinations in deaf people: insights into the nature of subvocal thought and sensory feedback loops. Schizophr. Bull. 32, 701-708.

Ballard, C. G., O’Brien, J. T., Swann, A. G., Thompson, P., Neill, D., and McKeith, I. G. (2001). The natural history of psychosis and depression in dementia with Lewy bodies and Alzheimer's disease: persistence and new cases over 1 year of follow-up. J. Clin. Psychiatry 62, 46-49.

Barber, P. O., and Lederman, S. J. (1988). Encoding direction in manipulatory space. J. Vis. Impair. Blind. 82, 99-106.

Bedny, M., Konkle, T., Pelphrey, K., Saxe, R., and Pascual-Leone, A. (2010). Sensitive period for a multimodal response in human visual motion area MT/MST. Curr. Biol. 20, 1900-1906.

Bellastella, A., Sinisi, A. A., Criscuolo, T., De Bellis, A., Carella, C., Iorio, S., et al. (1995). Melatonin and the pituitary-thyroid axis status in blind adults: a possible resetting after puberty. Clin. Endocrinol. (Oxf.) 43, 707-711.

\section{ACKNOWLEDGMENTS}

We thank Thomas Papathomas, Matt Roche, Keith Feigenson, James Gold, and Judy Thompson for their helpful comments on earlier drafts of this manuscript. We also thank Ms. Arwen Lockley for her helpful insights on blindness and schizophrenia, and the two reviewers for their helpful suggestions. This work was supported by a National Research Service Award (F32MH094102) to Brian P. Keane, and R01MH093439 to Steven M. Silverstein.

Bertolo, H., Paiva, T., Pessoa, L. Mestre, T., Marques, R., and Santos, R. (2003). Visual dream content, graphical representation and EEG alpha activity in congenitally blind subjects. Brain Res. Cogn. Brain Res. 15, 277-284.

Bleuler, E. (1950). Dementia Praecox or the Group of Schizophrenias. New York: International Universities Press.

Boksa, P. (2012). Abnormal synaptic pruning in schizophrenia: urban myth or reality? J. Psychiatry Neurosci. 37, 75-77.

Bolat, N., Dogangun, B., Yavuz, M. Demir, T., and Kayaalp, L. (2011). Depression and anxiety levels and self-concept characteristics of adolescents with congenital complete visual impairment. Turk. Psikiyatri. Derg. 22, 77-82.

Bonino, D., Ricciardi, E., Sani, L., Gentili, C., Vanello, N., Guazzelli, M., et al. (2008). Tactile spatial working memory activates the dorsal extrastriate cortical pathway in congenitally blind individuals. Arch. Ital. Biol. 146, 133-146.

Brahmbhatt, S. B., Haut, K., Csernansky, J. G., and Barch, D. M (2006). Neural correlates of verbal and nonverbal working memory deficits in individuals with schizophrenia and their highrisk siblings. Schizophr. Res. 87, 191-204.

Brebion, G., Amador, X., Smith, M. J., and Gorman, J. M. (1997). Mechanisms underlying memory impairment in schizophrenia. Psychol. Med. 27, 383-393.

Brebion, G., David, A. S., Jones, H. and Pilowsky, L. S. (2004). Semantic organization and verbal memory efficiency in patients with schizophrenia. Neuropsychology 18, 378-383.

Brewer, W. J., Wood, S. J., McGorry, P. D. Francey, S. M., Phillips, L. J., Yung, A. R., et al. (2003). Impairment of olfactory identification ability in individuals at ultra-high risk for psychosis who later develop schizophrenia. Am. J. Psychiatry 160, 1790-1794.

Bross, M. (1979). Residual sensory capacities of the deaf: a signal detection analysis of a visual discrimination task. Percept. Mot. Skills 48, 187-194.

Brown, R., Hobson, R. P., Lee, A., and Stevenson, J. (1997). Are there "autistic-like" features in congenitally blind children? J. Child Psychol. Psychiatry 38, 693-703.

Bruce, S. M. (2005). The impact of congenital deafblindness on the struggle to symbolism. Int. J. Disabil. Dev. Educ. 52, 223-251.

Bruder, G., Kayser, J., Tenke, C., Amador, X., Friedman, M., Sharif, Z., et al. (1999). Left temporal lobe dysfunction in schizophrenia: event-related potential and behavioral evidence from phonetic and tonal dichotic listening tasks. Arch. Gen. Psychiatry 56, 267-276.

Bull, R., Rathborn, H., and Clifford, B. R. (1983). The voice-recognition accuracy of blind listeners. Perception 12, 223-226.

Burton, H., Diamond, J. B., and McDermott, K. B. (2003). Dissociating cortical regions activated by semantic and phonological tasks: a FMRI study in blind and sighted people. J. Neurophysiol. 90, 1965-1982.

Butler, P. D., Silverstein, S. M., and Dakin, S. C. (2008). Visual perception and its impairment in schizophrenia. Biol. Psychiatry 64, 40-47.

Carr, V., and Wale, J. (1986). Schizophrenia: an information processing model. Aust. N. Z. J. Psychiatry 20, 136-155.

Carvill, S. (2001). Sensory impairments, intellectual disability and psychiatry. J. Intellect. Disabil. Res. 45, 467-483.

Cattaneo, Z., and Vecchi, T. (2011). Blind Vision. Cambridge: MIT Press.

Cattaneo, Z., Vecchi, T., Cornoldi, C., Mammarella, I., Bonino, D., Ricciardi, E., et al. (2008). Imagery and spatial processes in blindness and visual impairment. Neurosci. Biobehav. Rev. 32, 1346-1360.

Chapman, J. (1966). The early symptoms of schizophrenia. Br. J. Psychiatry 112, 225-251.

Chase, J. B. (1972). Retrolental Fibroplasia and Autistic Symptomatology. New York, NY: New York America Foundation for the Blind. 
Checkley, S. A., and Slade, A. P. (1979). Blindness and schizophrenia. Lancet 313, 730-731.

Chen, Q., He, S., Hu, X. L., Yu, J., Zhou, Y., Zheng, J., et al. (2007). Differential roles of NR2A- and NR2B-containing NMDA receptors in activity-dependent brain-derived neurotrophic factor gene regulation and limbic epileptogenesis. J. Neurosci. 27, 542-552.

Chen, W. S., and Bear, M. F. (2007). Activity-dependent regulation of NR2B translation contributes to metaplasticity in mouse visual cortex. Neuropharmacology 52, 200-214.

Chen, Y. (2011). Abnormal visual motion processing in schizophrenia: a review of research progress. Schizophr. Bull. 37, 709-715.

Chess, S. (1971). Autism in children with congenital rubella. J. Autism Child. Schizophr. 1, 33-47.

Chevigny, H., and Braverman, S. (1950). The Adjustment of the Blind. New Haven: Yale University Press.

Clark, A. (in press). Whatever (next)? Predictive brains, situated agents, and the future of cognitive science. Behav. Brain Sci.

Cobia, D. J., Smith, M. J., Wang, L., and Csernansky, J. G. (2012). Longitudinal progression of frontal and temporal lobe changes in schizophrenia. Schizophr. Res. 139, 1-6.

Cohen, J. D., and Servan-Schreiber, D. (1992). Context, cortex, and dopamine: a connectionist approach to behavior and biology in schizophrenia. Psychol. Rev. 99, 45-77.

Cohen, L. G., Celnik, P., Pascual-Leone, A., Corwell, B., Falz, L., Dambrosia, J., et al. (1997). Functional relevance of cross-modal plasticity in blind humans. Nature 389, 180-183.

Cohen, L. G., Weeks, R. A., Sadato, N., Celnik, P., Ishii, K., and Hallett, M. (1999). Period of susceptibility for cross-modal plasticity in the blind. Ann. Neurol. 45, 451-460.

Collignon, O., and De Volder, A. G. (2009). Further evidence that congenitally blind participants react faster to auditory and tactile spatial targets. Can. J. Exp. Psychol. 63, 287-293.

Collignon, O., Renier, L., Bruyer, R., Tranduy, D., and Veraart, C. (2006). Improved selective and divided spatial attention in early blind subjects. Brain Res. 1075, 175-182.

Collignon, O., Voss, P., Lassonde, M., and Lepore, F. (2009). Cross-modal plasticity for the spatial processing of sounds in visually deprived subjects. Exp. Brain Res. 192, 343-358.
Conklin, H. M., Curtis, C. E., Calkins, M. E., and Iacono, W. G. (2005). Working memory functioning in schizophrenia patients and their first-degree relatives: cognitive functioning shedding light on etiology. Neuropsychologia 43, 930-942.

Corlett, P. R., Frith, C. D., and Fletcher, P. C. (2009). From drugs to deprivation: a Bayesian framework for understanding models of psychosis. Psychopharmacology (Berl.) 206, 515-530.

Corlett, P. R., Honey, G. D., and Fletcher, P. C. (2007). From prediction error to psychosis: ketamine as a pharmacological model of delusions. J. Psychopharmacol. (Oxford) 21, 238-252.

Cornoldi, C., Calore, D., and Pra-Baldi, A. (1979). Imagery rating and recall in congenitally blind subjects. Percept. Mot. Skills 48, 627-639.

Cortese, L., Caligiuri, M. P., Malla, A. K., Manchanda, R., Takhar, J., and Haricharan, R. (2005). Relationship of neuromotor disturbances to psychosis symptoms in firstepisode neuroleptic-naive schizophrenia patients. Schizophr. Res. 75, 65-75.

Costafreda, S. G., Fu, C. H., Picchioni, M., Toulopoulou, T., McDonald, C., Kravariti, E., et al. (2011). Pattern of neural responses to verbal fluency shows diagnostic specificity for schizophrenia and bipolar disorder. BMC Psychiatry 11:18. doi:10.1186/1471-244X-11-18

Coyle, J. T. (2012). NMDA receptor and schizophrenia: a brief history. Schizophr. Bull. 38, 920-926.

Cuevas, I., Plaza, P., Rombaux, P., De Volder, A. G., and Renier, L. (2009). Odour discrimination and identification are improved in early blindness. Neuropsychologia 47, 3079-3083.

Cutting, J. (1985). The Psychology of Schizophrenia. Edinburgh: Livingstone.

Cuzzocrea, S., Costantino, G., Mazzon, E., and Caputi, A. P. (1999). Regulation of prostaglandin production in carrageenan-induced pleurisy by melatonin. J. Pineal Res. 27, 9-14.

Dammeyer, J. (2011). Mental and behavioral disorders among people with congenital deafblindness. Res. Dev. Disabil. 32, 571-575.

Dammeyer, J. (2012). Children with Usher syndrome: mental and behavioral disorders. Behav. Brain Funct. 8,16 .

Danckert, J., Saoud, M., and Maruff, P. (2004). Attention, motor control and motor imagery in schizophrenia: implications for the role of the parietal cortex. Schizophr. Res. 70, 241-261.

Daskalakis, Z. J., Christensen, B. K., Fitzgerald, P. B., and Chen, R. (2008). Dysfunctional neural plasticity in patients with schizophrenia. Arch. Gen. Psychiatry 65, 378-385

de La Serna, E., Andres-Perpina, S., Puig, O., Baeza, I., Bombin, I., Bartres-Faz, D., et al. (2013). Cognitive reserve as a predictor of two year neuropsychological performance in early onset first-episode schizophrenia. Schizophr. Res. 143, 125-131.

De Volder, A. G., Catalan-Ahumada, M., Robert, A., Bol, A., Labar, D. Coppens, A., et al. (1999). Changes in occipital cortex activity in early blind humans using a sensory substitution device. Brain Res. 826 128-134.

Dervaux, A., and Laqueille, X. (2008). [Smoking and schizophrenia: epidemiological and clinical features]. Encephale 34, 299-305.

Deutschlander, A., Stephan, T., Hufner, K., Wagner, J., Wiesmann, M. Strupp, M., et al. (2009). Imagined locomotion in the blind: an fMRI study. Neuroimage 45, 122-128.

Dima, D., Dietrich, D. E., Dillo, W., and Emrich, H. M. (2010). Impaired topdown processes in schizophrenia: a DCM study of ERPs. Neuroimage 52, 824-832.

Dima, D., Roiser, J. P., Dietrich, D. E., Bonnemann, C., Lanfermann, H., Emrich, H. M., et al. (2009). Understanding why patients with schizophrenia do not perceive the hollow-mask illusion using dynamic causal modelling. Neuroimage 46 , 1180-1186.

Dolan, R. J., Fletcher, P., Frith, C. D. Friston, K. J., Frackowiak, R. S., and Grasby, P. M. (1995). Dopaminergic modulation of impaired cognitive activation in the anterior cingulate cortex in schizophrenia. Nature 378 180-182.

Du Feu, M., and McKenna, P. J. (1999). Prelingually profoundly deaf schizophrenic patients who hear voices: a phenomenological analysis. Acto Psychiatr. Scand. 99, 453-459.

Dye, M. W., and Bavelier, D. (2010). Attentional enhancements and deficits in deaf populations: an integrative review. Restor. Neurol. Neurosci. 28, 181-192.

Eack, S. M., Hogarty, G. E., Cho, R. Y. Prasad, K. M., Greenwald, D. P., Hogarty, S. S., et al. (2010). Neuroprotective effects of cognitive enhancement therapy against gray matter loss in early schizophrenia: results from a 2 -year randomized controlled trial. Arch. Gen. Psychiatry 67, 674-682.
Eaton, W. W., Hayward, C., and Ram, R. (1992). Schizophrenia and rheumatoid arthritis: a review. Schizophr. Res. 6, 181-192.

Ehrsson, H. H., Spence, C., and Passingham, R. E. (2004). That's my hand! Activity in premotor cortex reflects feeling of ownership of a limb. Science 305, 875-877.

Ek, U., Fernell, E., Jacobson, L., and Gillberg, C. (1998). Relation between blindness due to retinopathy of prematurity and autistic spectrum disorders: a population based study. Dev. Med. Child Neurol. 40, 297-301.

Elbert, T., Sterr, A., Rockstroh, B., Pantev, C., Muller, M. M., and Taub, E. (2002). Expansion of the tonotopic area in the auditory cortex of the blind. J. Neurosci. 22, 9941-9944.

Feierman, J. R. (1982). Nocturnalism: an ethological theory of schizophrenia. Med. Hypotheses 9, 455-479.

Ffytche, D. H. (2007). Visual hallucinatory syndromes: past, present, and future. Dialogues Clin. Neurosci. 9, 173-189.

Fisher, M., Holland, C., Merzenich, M. M., and Vinogradov, S. (2009). Using neuroplasticity-based auditory training to improve verbal memory in schizophrenia. Am. J. Psychiatry 166, 805-811.

Fisher, M., Holland, C., Subramaniam, K., and Vinogradov, S. (2010). Neuroplasticity-based cognitive training in schizophrenia: an interim report on the effects 6 months later. Schizophr. Bull. 36, 869-879.

Fitzgerald, P. B., Brown, T. L., Marston, N. A., Oxley, T., De Castella, A., Daskalakis, Z. J., et al. (2004). Reduced plastic brain responses in schizophrenia: a transcranial magnetic stimulation study. Schizophr. Res. 71, 17-26.

Foucher, J. R., Lacambre, M., Pham, B. T., Giersch, A., and Elliott, M. A. (2007). Low time resolution in schizophrenia Lengthened windows of simultaneity for visual, auditory and bimodal stimuli. Schizophr. Res. 97, 118-127.

Fraiberg, S. (1977). Insights from the Blind. London: Souvenir.

Garg, A., Schwartz, D., and Stevens, A. A. (2007). Orienting auditory spatial attention engages frontal eye fields and medial occipital cortex in congenitally blind humans. Neuropsychologia 45, 2307-2321.

Geenens, D. L. (1999). "Neurobiological development and cognition in the deafblind," in A Guide to Planning and Support for Individuals Who are Deafblind, ed. J. M. 
McInnes (Toronto: University of Toronto Press), 150-174.

Genevsky, A., Garrett, C. T., Alexander, P. P., and Vinogradov, S. (2010). Cognitive training in schizophrenia: a neuroscience-based approach. Dialogues Clin. Neurosci. 12, 416-421.

Gold, R., Butler, P., Revheim, N., Leitman, D. I., Hansen, J. A., Gur, R. C., et al. (2012). Auditory emotion recognition impairments in schizophrenia: relationship to acoustic features and cognition. Am. J. Psychiatry 169, 424-432.

Goodale, M. A. (1993). Visual pathways supporting perception and action in the primate cerebral cortex. Curr. Opin. Neurobiol. 3, 578-585.

Goodale, M. A., Kroliczak, G., and Westwood, D. A. (2005). Dual routes to action: contributions of the dorsal and ventral streams to adaptive behavior. Prog. Brain Res. 149, 269-283.

Goodin-Jones, B. L., Eiben, L. A., and Anders, T. F. (1997). Maternal, wellbeing and sleep-wake behaviors in infants: an intervention using maternal odor. Infant Ment. Health J. 18, 378-393.

Gorwood, P., Pouchot, J., Vinceneux, P., Puechal, X., Flipo, R. M., De Bandt, M., et al. (2004). Rheumatoid arthritis and schizophrenia: a negative association at a dimensional level. Schizophr. Res. 66, 21-29.

Green, M. F. (1996). What are the functional consequences of neurocognitive deficits in schizophrenia? Am. J. Psychiatry 153, 321-330.

Green, M. F., Hugdahl, K., and Mitchell, S. (1994). Dichotic listening during auditory hallucinations in patients with schizophrenia. Am. J. Psychiatry 151, 357-362.

Griskova-Bulanova, I., Dapsys, K., Maciulis, V., and Arnfred, S. M. (2012). Closed eyes condition increases auditory brain responses in schizophrenia. Psychiatry Res. doi: 10.1016/j.pscychresns.2012.04.004

Harvey, P. D., Earle-Boyer, E. A., Weilgus, M. S., and Levinson, J. C. (1986). Encoding, memory, and thought disorder in schizophrenia and mania. Schizophr. Bull. 12, 252-261.

Hasan, A., Nitsche, M. A., Herrmann, M., Schneider-Axmann, T., Marshall, L., Gruber, O., et al. (2012). Impaired long-term depression in schizophrenia: a cathodal tDCS pilot study. Brain Stimul. 5, 475-483.

Hasan, A., Nitsche, M. A., Rein, B., Schneider-Axmann, T., Guse, B., Gruber, O., et al. (2011). Dysfunctional long-term potentiation-like plasticity in schizophrenia revealed by transcranial direct current stimulation. Behav. Brain Res. 224, 15-22.

Heinrichs, R. W., and Zakzanis, K. K. (1998). Neurocognitive deficit in schizophrenia: a quantitative review of the evidence. Neuropsychology 12 , 426-445.

Hemsley, D. R. (1996). Schizophrenia. A cognitive model and its implications for psychological intervention. Behav. Modif. 20, 139-169.

Herssens, J. (2010). "Haptic design research: a blind sense of place," in Proceedings of the 7th ARCC/EAAE 2010 International Conference on Architectural Research (Washington, DC: EAAE-ARCC). Available at: http: //www.aia.org/aiaucmp/groups/ aia/documents/pdf/aiab087187.pdf [accessed December 27, 2012].

Hertrich, I., Dietrich, S., Moos, A., Trouvain, J., and Ackermann, H. (2009). Enhanced speech perception capabilities in a blind listener are associated with activation of fusiform gyrus and primary visual cortex. Neurocase 15, 163-170.

Hirano, S., Hirano, Y., Maekawa, T., Obayashi, C., Oribe, N., Kuroki, T., et al. (2008). Abnormal neural oscillatory activity to speech sounds in schizophrenia: a magnetoencephalography study. J. Neurosci. 28, 4897-4903.

Horan, W. P., Braff, D. L., Nuechterlein, K. H., Sugar, C. A., Cadenhead, K. S., Calkins, M. E., et al. (2008). Verbal working memory impairments in individuals with schizophrenia and their first-degree relatives: findings from the Consortium on the Genetics of Schizophrenia. Schizophr. Res. 103, 218-228.

Horrobin, D. F. (1979). Schizophrenia: reconciliation of the dopamine, prostaglandin, and opioid concepts and the role of the pineal. Lancet 1, 529-531.

Horton, H. K., and Silverstein, S. M. (2007). Cognition and functional outcome among deaf and hearing people with schizophrenia. Schizophr. Res. 94, 187-196.

Horton, H. K., and Silverstein, S. M. (2011). Visual context processing deficits in schizophrenia: effects of deafness and disorganization. Schizophr. Bull. 37, 716-726.

Hotting, K., and Roder, B. (2004). Hearing cheats touch, but less in congenitally blind than in sighted individuals. Psychol. Sci. 15, 60-64.

Hugdahl, K., Ek, M., Takio, F., Rintee, T., Tuomainen, J., Haarala, C., et al. (2004). Blind individuals show enhanced perceptual and attentional sensitivity for identification of speech sounds. Brain Res. Cogn. Brain Res. 19, 28-32.

Hull, T., and Mason, H. (1995). Performance of blind children on digit span tests. J. Vis. Impair. Blind. 89, 166-169.

Ilankovic, L. M., Allen, P. P., Engel, R., Kambeitz, J., Riedel, M., Muller, N., et al. (2011). Attentional modulation of external speech attribution in patients with hallucinations and delusions. Neuropsychologia 49 , 805-812.

Iyer, D., Boutros, N. N., and Zouridakis, G. (2012). Single-trial analysis of auditory evoked potentials improves separation of normal and schizophrenia subjects. Clin. Neurophysiol. 123 1810-1820.

Javitt, D. C., Strous, R. D., Grochowski, S., Ritter, W., and Cowan N. (1997). Impaired precision, but normal retention, of auditory sensory ("echoic") memory information in schizophrenia. J. Abnorm. Psychol. 106, 315-324.

Jiang, J., Zhu, W., Shi, F., Liu, Y., Li, J. Qin, W., et al. (2009). Thick visual cortex in the early blind. J. Neurosci. 29, 2205-2211.

Johns, L. C., Rossell, S., Frith, C., Ahmad, F., Hemsley, D., Kuipers, E., et al. (2001). Verbal self-monitoring and auditory verbal hallucinations in patients with schizophrenia. Psychol. Med. 31, 705-715.

Kallstrand, J., Montnemery, P., Nielzen, S., and Olsson, O. (2002). Auditory masking experiments in schizophrenia. Psychiatry Res 113, 115-125.

Kamath, V., Turetsky, B. I., Calkins, M. E., Kohler, C. G., Conroy, C. G., Borgmann-Winter, K., et al. (2011). Olfactory processing in schizophrenia, non-ill first-degree family members, and young people at-risk for psychosis. World J. Biol. Psychiatry. PMID:22070564. [Epub ahead of print].

Kantrowitz, J. T., Leitman, D. I. Lehrfeld, J. M., Laukka, P., Juslin, P. N., Butler, P. D., et al. (2013). Reduction in tonal discriminations predicts receptive emotion processing deficits in schizophrenia and schizoaffective disorder. Schizophr Bull. 39, 86-93.

Kayser, J., Bruder, G. E., Tenke, C. E. Stuart, B. K., Amador, X. F., and Gorman, J. M. (2001). Event-related brain potentials (ERPs) in schizophrenia for tonal and phonetic oddball tasks. Biol. Psychiatry 49, 832-847.

Keeler, W. R. (1958). Autistic Patterns and Defective Communication in Blind Children with Retrolental Fibroplasia. New York: Grune \& Stratton.

Keller, H. (1908). The World I Live In. New York: Grosset and Dunlop.

Khan, R. (in press). "Why Kraepelin was right: schizophrenia as a cognitive disorder," in Schizophrenia: Evolution and Synthesis, eds S. Silverstein, B. Moghaddam, and T. Wykes (Cambridge: MIT Press).

Kim, D., Burge, J., Lane, T., Pearlson, G. D., Kiehl, K. A., and Calhoun, V. D. (2008). Hybrid ICABayesian network approach reveals distinct effective connectivity differences in schizophrenia. Neuroimage 42, 1560-1568.

King, J. P., Christensen, B. K., and Westwood, D. A. (2008). Grasping behavior in schizophrenia suggests selective impairment in the dorsal visual pathway. J. Abnorm. Psychol. 117, 799-811.

Kitson, N., and Fry, R. (1990). Prelingual deafness and psychiatry. Br. J. Hosp. Med. 44, 353-356.

Klosterkotter, J. (1992). The meaning of basic symptoms for the genesis of the schizophrenic nuclear syndrome. Jpn. J. Psychiatry Neurol. 46, 609-630.

Knight, R. A. (1984). “Converging models of cognitive deficits in schizophrenia," in Nebraska Symposium on Motivation: Theories of Schizophrenia and Psychosis, ed. J. C. W. Spaulding (Lincoln, NE: University of Nebraska Press), 93-156.

Knight, R. A., and Silverstein, S. M. (1998). "The role of cognitive psychology in guiding research on cognitive deficits in schizophrenia," in Origins and Development of Schizophrenia: Advances in Experimental Psychopathology, ed. R. H. D. M. Lenzenweger (Washington, DC:APA Press), 247-295.

Kocourkova, J., Soltysova, M. Mohaplova, M., and Hrdlicka, M. (2011). Anorexia nervosa in a blind girl. Neuro Endocrinol. Lett. 32, 748-750.

Koerts, J., Tucha, L., Lange, K. W., and Tucha, O. (2012). The influence of cognitive reserve on cognition in Parkinson's disease. J. Neural Transm. PMID:23212723. [Epub ahead of print].

Kraepelin, E. (1903). Lehrbuch der Psychiatrie. Leipzig: Barth.

Kreher, D. A., Holcomb, P. J., Goff, D., and Kuperberg, G. R. (2008). Neural evidence for faster and further automatic spreading activation in schizophrenic thought disorder. Schizophr. Bull. 34, 473-482. 
Kujala, T., Alho, K., Kekoni, J., Hamalainen, H., Reinikainen, K., Salonen, O., et al. (1995). Auditory and somatosensory eventrelated brain potentials in early blind humans. Exp. Brain Res. 104, 519-526.

Kupers, R., Beaulieu-Lefebvre, M., Schneider, F. C., Kassuba, T., Paulson, O. B., Siebner, H. R., et al. (2011). Neural correlates of olfactory processing in congenital blindness. Neuropsychologia 49, 2037-2044.

Lalor, E. C., De Sanctis, P., Krakowski, M. I., and Foxe, J. J. (2012). Visual sensory processing deficits in schizophrenia: is there anything to the magnocellular account? Schizophr. Res. 139, 246-252.

Landgraf, S., Amado, I., Berthoz, A., Krebs, M., and Van Der Meer, E. (2012). Cognitive identify in schizophrenia: vision, space, and body perception from prodrome to syndrome. Curr. Psychiatry Rev. 8, 119-139.

Landgraf, S., Steingen, J., Eppert, Y., Niedermeyer, U., Van Der Meer, E., and Krueger, F. (2011). Temporal information processing in short- and long-term memory of patients with schizophrenia. PLoS ONE 6:e26140. doi:10.1371/journal.pone.0026140

Leclerc, C., Segalowitz, S. J., Desjardins, J., Lassonde, M., and Lepore, F. (2005). EEG coherence in early-blind humans during sound localization. Neurosci. Lett. 376, 154-159.

Lee, H., Dvorak, D., Kao, H.-Y., Duffy, A. M., Scharfman, H. E., and Fenton, A. A. (2012). Early cognitive experience prevents adult deficits in a neurodevelopmental schizophrenia model. Neuron. 75, 714-724.

Leitman, D. I., Hoptman, M. J., Foxe, J. J., Saccente, E., Wylie, G. R., Nierenberg, J., et al. (2007). The neural substrates of impaired prosodic detection in schizophrenia and its sensorial antecedents. Am. J. Psychiatry 164, 474-482.

Leitman, D. I., Wolf, D. H., Laukka, P., Ragland, J. D., Valdez, J. N., Turetsky, B. I., et al. (2011). Not pitch perfect: sensory contributions to affective communication impairment in schizophrenia. Biol. Psychiatry 70, 611-618.

Lerner, I., Bentin, S., and Shriki, O. (2012). Excessive attractor instability accounts for semantic priming in schizophrenia. PLoS ONE 7:e40663. doi:10.1371/journal.pone.0040663

Li, C. S., Chen, M. C., Yang, Y. Y., and Tsay, P. K. (2002). Altered performance of schizophrenia patients in an auditory detection and discrimination task: exploring the 'selfmonitoring' model of hallucination. Schizophr. Res. 55, 115-128.

Light, G. A., and Braff, D. L. (2005a). Mismatch negativity deficits are associated with poor functioning in schizophrenia patients. Arch. Gen. Psychiatry 62, 127-136.

Light, G. A., and Braff, D. L. (2005b). Stability of mismatch negativity deficits and their relationship to functional impairments in chronic schizophrenia. Am. J. Psychiatry 162, 1741-1743.

Maher, B. A. (1974). Delusional thinking and perceptual disorder. J. Individ. Psychol. 30, 98-113.

Mahncke, H. W., Connor, B. B., Appelman, J., Ahsanuddin, O. N., Hardy, J. L., Wood, R. A., et al. (2006). Memory enhancement in healthy older adults using a brain plasticity-based training program: a randomized, controlled study. Proc. Natl. Acad. Sci. U.S.A. 103, 12523-12528.

Matteau, I., Kupers, R., Ricciardi, E., Pietrini, P., and Ptito, M. (2010). Beyond visual, aural and haptic movement perception: hMT + is activated by electrotactile motion stimulation of the tongue in sighted and in congenitally blind individuals. Brain Res. Bull. 82, 264-270.

McGorry, P. D. (2010). Risk syndromes, clinical staging and DSM V: new diagnostic infrastructure for early intervention in psychiatry. Schizophr. Res. 120, 49-53.

McGorry, P. D., Nelson, B., Goldstone, S., and Yung, A. R. (2010). Clinical staging: a heuristic and practical strategy for new research and better health and social outcomes for psychotic and related mood disorders. Can. J. Psychiatry 55, 486-497.

McNeil, T. F., and Kaij, L. (1987). Swedish high-risk study: sample characteristics at age 6. Schizophr. Bull. 13, 373-381.

Mears, R. P., and Spencer, K. M. (2012). Electrophysiological assessment of auditory stimulus-specific plasticity in schizophrenia. Biol. Psychiatry 71, 503-511.

Mittal, V. A., Neumann, C., Saczawa, M., and Walker, E. F. (2008). Longitudinal progression of movement abnormalities in relation to psychotic symptoms in adolescents at high risk of schizophrenia. Arch. Gen. Psychiatry 65, 165-171

Morgan, C., O’Donovan, M., Bittner, R., Cadenhead, K., Jones, P., McGrath, J., et al. (in press). "How can risk and resilience factors be leveraged to optimize discovery pathways," in
Schizophrenia: Evolution and Synthesis, eds M. B. Silverstein and T. Wykes (Cambridge: MIT Press).

Mors, O., Mortensen, P. B., and Ewald, H. (1999). A populationbased register study of the association between schizophrenia and rheumatoid arthritis. Schizophr. Res. 40, 67-74.

Muchnik, C., Efrati, M., Nemeth, E. Malin, M., and Hildesheimer, M. (1991). Central auditory skills in blind and sighted subjects. Scand. Audiol. 20, 19-23.

Muller, N., Myint, A. M., and Schwarz, M. J. (2012). Inflammation in schizophrenia. Adv. Protein Chem. Struct. Biol. 88, 49-68.

Musial, F., Kolassa, I. T., Sulzenbruck, S., and Miltner, W. H. (2007). A case of spider phobia in a congenitally blind person. Psychiatry Res. 153, 97-101.

Myin-Germeys, I., and van Os, J. (2007). Stress-reactivity in psychosis: evidence for an affective pathway to psychosis. Clin. Psychol. Rev. 27, 409-424.

Naslund, B., Persson-Blennow, I., McNeil, T., Kaij, L., and MalmquistLarsson, A. (1984). Offspring of women with nonorganic psychosis: infant attachment to the mother at one year of age. Acta Psychiatr. Scand. 69, 231-241.

Neumann, C. S., Grimes, K., Walker, E. F., and Baum, K. (1995). Developmental pathways to schizophrenia: behavioral subtypes. J. Abnorm. Psychol. 104, 558-566.

Ngan, E. T., Vouloumanos, A., Cairo, T. A., Laurens, K. R., Bates, A. T., Anderson, C. M., et al. (2003). Abnormal processing of speech during oddball target detection in schizophrenia. Neuroimage 20, 889-897.

Nguyen, A. D., Shenton, M. E., and Levitt, J. J. (2010). Olfactory dysfunction in schizophrenia: a review of neuroanatomy and psychophysiological measurements. Harv. Rev. Psychiatry 18, 279-292.

Niemeyer, W., and Starlinger, I. (1981). Do the blind hear better - investigations on auditory processing in congenital or early acquired blindness. II. Central functions. Audiology 20, 510-515.

Noppeney, U., Friston, K. J., and Price, C. J. (2003). Effects of visual deprivation on the organization of the semantic system. Brain 126, 1620-1627.

Nuechterlein, K. H., Subotnik, K. L., Ventura, J., Green, M. F., GretchenDoorly, D., and Asarnow, R. F. (2012). The puzzle of schizophrenia: tracking the core role of cognitive deficits. Dev. Psychopathol. 24, 529-536.

Oken, R. J., and Schulzer, M. (1999). At issue: schizophrenia and rheumatoid arthritis: the negative association revisited. Schizophr. Bull. 25, 625-638.

Ortiz, T., Poch, J., Santos, J. M., Requena, C., Martinez, A. M., Ortiz-Teran, L., et al. (2011). Recruitment of occipital cortex during sensory substitution training linked to subjective experience of seeing in people with blindness. PLoS ONE 6:e23264. doi:10.1371/journal.pone.0023264

Oxley, T., Fitzgerald, P. B., Brown, T. L., De Castella, A., Daskalakis, Z. J., and Kulkarni, J. (2004). Repetitive transcranial magnetic stimulation reveals abnormal plastic response to premotor cortex stimulation in schizophrenia. Biol. Psychiatry 56, 628-633.

Palmer, B. W., Dawes, S. E., and Heaton, R. K. (2009). What do we know about neuropsychological aspects of schizophrenia? Neuropsychol. Rev. 19, 365-384.

Peck, J. S., Legoff, D. B., Ahmed, I., and Goebert, D. (2004). Cognitive effects of exogenous melatonin administration in elderly persons: a pilot study. Am. J. Geriatr. Psychiatry 12, 432-436.

Perez-Pereira, M., and Conti-Ramsden, G. (1999). Social Interaction and Language Development in Blind Children. Hove: Psychology Press.

Perrin, M. A., Butler, P. D., Dicostanzo, J., Forchelli, G., Silipo, G., and Javitt, D. C. (2010). Spatial localization deficits and auditory cortical dysfunction in schizophrenia. Schizophr. Res. 124, 161-168.

Persson-Blennow, I., Naslund, B., McNeil, T. F., Kaij, L., and Malmquist-Larsson, A. (1984). Offspring of women with nonorganic psychosis: mother-infant interaction at three days of age. Acta Psychiatr. Scand. 70, 149-159.

Petkova, V. I., Zetterberg, H., and Ehrsson, H. H. (2012). Rubber hands feel touch, but not in blind individuals. PLOS ONE 7:e35912. doi:10.1371/journal.pone.0035912

Phillips, W. A., and Silverstein, S. M. (2003). Convergence of biological and psychological perspectives on cognitive coordination in schizophrenia. Behav. Brain Sci. 26, 65-82; discussion 82-137.

Pietrini, P., Furey, M. L., Ricciardi, E., Gobbini, M. I., Wu, W. H., Cohen, L., et al. (2004). Beyond sensory images: object-based representation in the human ventral pathway. 
Proc. Natl. Acad. Sci. U.S.A. 101, 5658-5663.

Pietrini, P., Ptito, M., and Kupers, R. (2009). Blindness and Consciousness: New Light from the Dark. Amsterdam: Elsevier.

Plomp, G., Roinishvili, M., Chkonia, E., Kapanadze, G., Kereselidze, M., Brand, A., et al. (2012). Electrophysiological evidence for ventral stream deficits in schizophrenia patients. Schizophr. Bull. PMID:22258884. [Epub ahead of print].

Polley, D. B., Steinberg, E. E., and Merzenich, M. M. (2006). Perceptual learning directs auditory cortical map reorganization through top-down influences. J. Neurosci. 26, 4970-4982.

Pring, L. (1988). The 'reversegeneration' effect: a comparison of memory performance between blind and sighted children. Br. J. Psychol. 79(Pt 3), 387-400.

Proksch, J., and Bavelier, D. (2002). Changes in the spatial distribution of visual attention after early deafness. J. Cogn. Neurosci. 14, 687-701.

Ptito, M., Fumal, A., De Noordhout, A. M., Schoenen, J., Gjedde, A., and Kupers, R. (2008). TMS of the occipital cortex induces tactile sensations in the fingers of blind Braille readers. Exp. Brain Res. 184, 193-200.

Ptito, M., Matteau, I., Gjedde, A., and Kupers, R. (2009). Recruitment of the middle temporal area by tactile motion in congenital blindness. Neuroreport 20, 543-547.

Ptito, M., Matteau, I., Zhi Wang, A., Paulson, O. B., Siebner, H. R., and Kupers, R. (2012). Crossmodal recruitment of the ventral visual stream in congenital blindness. Neural Plast. 2012, 304045.

Putzhammer, A., and Klein, H. E. (2006). Quantitative analysis of motor disturbances in schizophrenic patients. Dialogues Clin. Neurosci. 8, 123-130.

Rabinowicz, E. F., Silipo, G., Goldman, R., and Javitt, D. C. (2000). Auditory sensory dysfunction in schizophrenia: imprecision or distractibility? Arch. Gen. Psychiatry 57, 1149-1155.

Raz, N., Amedi, A., and Zohary, E. (2005). V1 activation in congenitally blind humans is associated with episodic retrieval. Cereb. Cortex 15, 1459-1468.

Raz, N., Striem, E., Pundak, G., Orlov, T., and Zohary, E. (2007). Superior serial memory in the blind: a case of cognitive compensatory adjustment. Curr. Biol. 17, 1129-1133.

Rettenbach, R., Diller, G., and Sireteanu, R. (1999). Do deaf people see better? Texture segmentation and visual search compensate in adult but not in juvenile subjects. J. Cogn. Neurosci. 11, 560-583.

Rigucci, S., Rossi-Espagnet, C., Ferracuti, S., De Carolis, A., Corigliano, V., Carducci, F., et al. (2012). Anatomical substrates of cognitive and clinical dimensions in first episode schizophrenia. Acta Psychiatr. Scand. doi: 10.1111/acps.12051

Riscalla, L. M. (1980). Blindness and schizophrenia. Med. Hypotheses 6, 1327-1328.

Roder, B., Kusmierek, A., Spence, C. and Schicke, T. (2007). Developmental vision determines the reference frame for the multisensory control of action. Proc. Natl. Acad. Sci. U.S.A. 104, 4753-4758.

Roder, B., and Neville, H. (2003). Developmental Functional Plasticity. Amsterdam: Elsevier.

Roder, B., Rosler, F., and Hennighausen, E. (1997). Different cortical activation patterns in blind and sighted humans during encoding and transformation of haptic images. Psychophysiology 34, 292-307.

Roder, B., Rosler, F., Hennighausen, E., and Nacker, F. (1996). Eventrelated potentials during auditory and somatosensory discrimination in sighted and blind human subjects. Brain Res. Cogn. Brain Res. 4, 77-93.

Roder, B., Rosler, F., and Neville, H. J. (1999). Effects of interstimulus interval on auditory event-related potentials in congenitally blind and normally sighted humans. Neurosci. Lett. 264, 53-56.

Roder, B., Rosler, F., and Neville, H. J. (2001). Auditory memory in congenitally blind adults: a behavioral-electrophysiological investigation. Brain Res. Cogn. Brain Res. 11, 289-303.

Roder, B., Rosler, F., and Spence, C. (2004). Early vision impairs tactile perception in the blind. Curr. Biol. 14, 121-124.

Roder, B., Stock, O., Bien, S., Neville, H., and Rosler, F. (2002). Speech processing activates visual cortex in congenitally blind humans. Eur. J. Neurosci. 16, 930-936.

Rogers, S. J., and Newhart-Larson, S. (1989). Characteristics of infantile autism in five children with Leber's congenital amaurosis. Dev. Med. Child Neurol. 31, 598-608.

Rojas, D. C., Slason, E., Teale, P. D., and Reite, M. L. (2007). Neuromagnetic evidence of broader auditory cortical tuning in schizophrenia. Schizophr. Res. 97, 206-214.

Rokem, A., and Ahissar, M. (2009). Interactions of cognitive and auditory abilities in congenitally blind individuals. Neuropsychologia 47, 843-848.

Salillas, E., Grana, A., El-Yagoubi, R., and Semenza, C. (2009). Numbers in the blind's “eye". PLoS ONE 4:e6357. doi:10.1371/journal.pone.0006357

Sanders, G. S., Platek, S. M., and Gallup, G. G. (2003). No blind schizophrenics: are NMDA-receptor dynamics involved? Behav. Brain Sci. 26, 103.

Sathian, K. (2005). Visual cortical activity during tactile perception in the sighted and the visually deprived. Dev. Psychobiol. 46, 279-286.

Schenkel, L. S., and Silverstein, S. M. (2004). Dimensions of premorbid functioning in schizophrenia: a review of neuromotor, cognitive, social, and behavioral domains. Genet. Soc. Gen. Psychol. Monogr. 130, 241-270.

Schiffman, J., Maeda, J. A., Hayashi, K., Michelsen, N., Sorensen, H. J., Ekstrom, M., et al. (2006). Premorbid childhood ocular alignment abnormalities and adult schizophrenia-spectrum disorder. Schizophr. Res. 81, 253-260.

Scholes, K. E., and Martin-Iverson, M. T. (2010). Disturbed prepulse inhibition in patients with schizophrenia is consequential to dysfunction of selective attention. Psychophysiology 47, 223-235.

Schubert, E. W., Henriksson, K. M., and McNeil, T. F. (2005). A prospective study of offspring of women with psychosis: visual dysfunction in early childhood predicts schizophreniaspectrum disorders in adulthood. Acta Psychiatr. Scand. 112, 385-393.

Sehatpour, P., Dias, E. C., Butler, P. D. Revheim, N., Guilfoyle, D. N., Foxe, J. J., et al. (2010). Impaired visual object processing across an occipitalfrontal-hippocampal brain network in schizophrenia: an integrated neuroimaging study. Arch. Gen. Psychiatry 67, 772-782.

Sevik, A. E., Anil Yagcioglu, A. E., Yagcioglu, S., Karahan, S., Gurses, N. and Yildiz, M. (2011). Neuropsychological performance and auditory event related potentials in schizophrenia patients and their siblings: a family study. Schizophr. Res. 130, 195-202.

Shamma, S. A., Elhilali, M., and Micheyl, C. (2011). Temporal coherence and attention in auditory scene analysis. Trends Neurosci. 34, 114-123.

Sharma, A. K., Mehta, A. K., Rathor, N., Chalawadi Hanumantappa, M. K., Khanna, N., and Bhattacharya, S. K. (2012). Melatonin attenuates cognitive dysfunction and reduces neural oxidative stress induced by phosphamidon. Fundam. Clin. Pharmacol. doi:10.1111/j.14728206.2011.00977.x

Sharp, C. W. (1993). Anorexia nervosa and depression in a woman blind since the age of nine months. Can. J. Psychiatry 38, 469-471.

Siekmeier, P. J., and Hoffman, R. E. (2002). Enhanced semantic priming in schizophrenia: a computer model based on excessive pruning of local connections in association cortex. Br. J. Psychiatry 180, 345-350.

Silver, H., Feldman, P., Bilker, W., and Gur, R. C. (2003). Working memory deficit as a core neuropsychological dysfunction in schizophrenia. Am. J. Psychiatry 160, 1809-1816.

Silverstein, S. M. (in press). Cognitive coordination and psychotic phenomena pose challenges to Clark's theory emphasizing propagation of prediction error and inhibition of correlated stimuli. Behav. Brain Sci.

Silverstein, S. M., Berten, S., Essex, B., Kovacs, I., Susmaras, T., and Little, D. M. (2009). An fMRI examination of visual integration in schizophrenia. J. Integr. Neurosci. 8, 175-202.

Silverstein, S. M., Jaeger, J., DonovanLepore, A. M., Wilkniss, S. M., Savitz, A., Malinovsky, I., et al. (2010). A comparative study of the MATRICS and IntegNeuro cognitive assessment batteries. J. Clin. Exp. Neuropsychol. 32, 937-952.

Silverstein, S. M., and Keane, B. P. (2009). Perceptual organization in schizophrenia: plasticity and staterelated change. Learn. Percept. 1, 229-261.

Silverstein, S. M., and Keane, B. P. (2011a). Perceptual organization impairment in schizophrenia and associated brain mechanisms: review of research from 2005 to 2010. Schizophr. Bull. 37, 690-699.

Silverstein, S. M., and Keane, B. P. (2011b). Vision science and schizophrenia research: toward a re-view of the disorder editors' introduction to special section. Schizophr. Bull.37, 681-689.

Silverstein, S. M., Schenkel, L. S., Valone, C., and Nuernberger, S. W. (1998). Cognitive deficits and psychiatric rehabilitation outcomes in schizophrenia. Psychiatr. Q. 69, 169-191.

Slotnick, S. D., Thompson, W. L., and Kosslyn, S. M. (2005). Visual mental imagery induces retinotopically organized activation of early visual areas. Cereb. Cortex 15, 1570-1583.

Solovay, M. R., Shenton, M. E., and Holzman, P. S. (1987). Comparative studies of thought disorders. I. Mania and schizophrenia. Arch. Gen. Psychiatry 44, 13-20. 
Steffener, J., and Stern, Y. (2012). Exploring the neural basis of cognitive reserve in aging. Biochim. Biophys. Acta 1822, 467-473.

Stern, Y. (2012). Cognitive reserve in ageing and Alzheimer's disease. Lancet Neurol. 11, 1006-1012.

Sterr, A., Green, L., and Elbert, T. (2003). Blind Braille readers mislocate tactile stimuli. Biol. Psychol. 63, 117-127.

Sterr, A., Muller, M. M., Elbert, T., Rockstroh, B., Pantev, C., and Taub, E. (1998). Perceptual correlates of changes in cortical representation of fingers in blind multifinger Braille readers. J. Neurosci. 18, 4417-4423.

Stevens, A. A., and Weaver, K. (2005). Auditory perceptual consolidation in early-onset blindness. Neuropsychologia 43, 1901-1910.

Stevens, A. A., and Weaver, K. E. (2009). Functional characteristics of auditory cortex in the blind. Behav. Brain Res. 196, 134-138.

Stewart, R. H., and Sardo, R. (1965). The psychotherapy of a blind schizophrenic child. J. Am. Acad. Child Psychiatry 4, 123-132.

Stolt, P., Bengtsson, C., Nordmark, B., Lindblad, S., Lundberg, I., Klareskog, L., et al. (2003). Quantification of the influence of cigarette smoking on rheumatoid arthritis: results from a population based case-control study, using incident cases. Ann. Rheum. Dis. 62, 835-841.

Sullivan, R. (2000). Review: Olfaction in the Human Infant. New York: The Fragrance Foundation. Available at: http: //www.senseofsmell.org/research/R. Sullivan-White-Paper.pdf

Sullivan, R. M. (2003). Developing a sense of safety: the neurobiology of neonatal attachment. Ann. N. Y. Acad. Sci. 1008, 122-131.

Sullivan, R. M., and Toubas, P. (1998). Clinical usefulness of maternal odor in newborns: soothing and feeding preparatory responses. Biol. Neonate $74,402-408$

Tamminga, C. (2013). Psychosis is emerging as a learning and memory disorder. Neuropsychopharmacol. Rev. 38, 247.

Tek, C., Gold, J., Blaxton, T., Wilk, C., McMahon, R. P., and Buchanan, R. W. (2002). Visual perceptual and working memory impairments in schizophrenia. Arch. Gen. Psychiatry 59, 146-153.

Temple, E., Deutsch, G. K., Poldrack, R. A., Miller, S. L., Tallal, P., Merzenich, M. M., et al. (2003). Neural deficits in children with dyslexia ameliorated by behavioral remediation: evidence from functional MRI. Proc. Natl. Acad. Sci. U.S.A. 100, 2860-2865.

Tendolkar, I., Ruhrmann, S., Brockhaus, A., Pukrop, R., and Klosterkotter, J. (2002). Remembering or knowing: electrophysiological evidence for an episodic memory deficit in schizophrenia. Psychol. Med. 32, 1261-1271.

Thakkar, K. N., Nichols, H. S., McIntosh, L. G., and Park, S. (2011). Disturbances in body ownership in schizophrenia: evidence from the rubber hand illusion and case study of a spontaneous out-of-body experience. PLoS ONE 6:e27089. doi:10.1371/journal.pone.0027089

Thewissen, V., Myin-Germeys, I., Bentall, R., De Graaf, R., Vollebergh, W., and Van Os, J. (2005). Hearing impairment and psychosis revisited. Schizophr. Res. 76 99-103.

Turetsky, B. I., Bilker, W. B., Siegel, S. J., Kohler, C. G., and Gur, R. E. (2009). Profile of auditory informationprocessing deficits in schizophrenia. Psychiatry Res. 165, 27-37.

Uhlhaas, P. J., and Mishara, A. L. (2007). Perceptual anomalies in schizophrenia: integrating phenomenology and cognitive neuroscience. Schizophr. Bull. 33, 142-156.

Uhlhaas, P. J., and Silverstein, S. M. (2005). Perceptual organization in schizophrenia spectrum disorders: empirical research and theoretical implications. Psychol. Bull. 131, 618-632.

Ullman, S. (1984). Visual routines. Cognition 18, 97-159.

Umbricht, D., Koller, R., Schmid, L., Skrabo, A., Grubel, C., Huber, T., et al. (2003). How specific are deficits in mismatch negativity generation to schizophrenia? Biol. Psychiatry 53, 1120-1131.

Van Snellenberg, J. X. (2009). Working memory and long-term memory deficits in schizophrenia: is there a common substrate? Psychiatry Res. 174, 89-96.
Vanlierde, A., De Volder, A. G., Wanet-Defalque, M. C., and Veraart, C. (2003). Occipito-parietal cortex activation during visuospatial imagery in early blind humans. Neuroimage 19, 698-709.

Vecchi, T., Tinti, C., and Cornoldi, C. (2004). Spatial memory and integration processes in congenital blindness. Neuroreport 15 2787-2790.

Velasques, B., Machado, S., Paes, F., Cunha, M., Sanfim, A., Budde, H., et al. (2011). Sensorimotor integration and psychopathology: motor control abnormalities related to psychiatric disorders. World J. Biol. Psychiatry 12, 560-573.

Vercammen, A., De Haan, E. H., and Aleman, A. (2008). Hearing a voice in the noise: auditory hallucinations and speech perception. Psychol. Med. 38, 1177-1184.

Wakefield, C. E., Homewood, J., and Taylor, A. J. (2004). Cognitive compensations for blindness in children: an investigation using odour naming. Perception 33, 429-442.

Wan, C. Y., Wood, A. G., Reutens, D. C. and Wilson, S. J. (2010). Early but not late-blindness leads to enhanced auditory perception. Neuropsychologia 48, 344-348.

Ward, J., and Meijer, P. (2010). Visual experiences in the blind induced by an auditory sensory substitution device. Conscious. Cogn. 19 492-500.

Ward, P. B., Catts, S. V., Fox, A. M., Michie, P. T., and McConaghy, N. (1991). Auditory selective attention and event-related potentials in schizophrenia. Br. J. Psychiatry 158 534-539.

Weiss, K. M. (1989). Advantages of abandoning symptom-based diagnostic systems of research in schizophrenia. Am. J. Orthopsychiatry 59, 324-330.

Williams, L. E., Light, G. A., Braff, D. L., and Ramachandran, V. S. (2010). Reduced multisensory integration in patients with schizophrenia on a target detection task. Neuropsychologia 48, 3128-3136.

Williams-Gray, C. H., Foltynie, T., Lewis, S. J., and Barker, R. A. (2006). Cognitive deficits and psychosis in Parkinson's disease: a review of pathophysiology and therapeutic options. CNS Drugs 20, 477-505.
Wing, L. (1969). The handicaps of autistic children - a comparative study. J. Child. Psychol. Psychiatry 10, 1-40.

Wong, M., Gnanakumaran, V., and Goldreich, D. (2011). Tactile spatial acuity enhancement in blindness: evidence for experience-dependent mechanisms. J. Neurosci. 31, 7028-7037.

Yung, A. R., and Nelson, B. (2011). Young people at ultra high risk for psychosis: a research update. Early Interv. Psychiatry 5(Suppl 1), 52-57.

Zhou, X., Panizzutti, R., De VillersSidani, E., Madeira, C., and Merzenich, M. M. (2011). Natural restoration of critical period plasticity in the juvenile and adult primary auditory cortex. J. Neurosci. 31, 5625-5634.

Zimler, J., and Keenan, J. M. (1983). Imagery in the congenitally blind: how visual are visual images? J. Exp. Psychol. Learn. Mem. Cogn. 9, 269-282.

Zimmer, U., Lewald, J., Erb, M., Grodd, W., and Karnath, H. O. (2004). Is there a role of visual cortex in spatial hearing? Eur. J. Neurosci. 20, 3148-3156.

Conflict of Interest Statement: The authors declare that the research was conducted in the absence of any commercial or financial relationships that could be construed as a potential conflict of interest.

Received: 03 November 2012; accepted: 31 December 2012; published online: 21 January 2013.

Citation: Silverstein SM, Wang $Y$ and Keane BP (2013) Cognitive and neuroplasticity mechanisms by which congenital or early blindness may confer a protective effect against schizophrenia. Front. Psychology 3:624. doi: 10.3389/fpsyg.2012.00624

This article was submitted to Frontiers in Psychopathology, a specialty of Frontiers in Psychology.

Copyright () 2013 Silverstein, Wang and Keane. This is an open-access article distributed under the terms of the Creative Commons Attribution License, which permits use, distribution and reproduction in other forums, provided the original authors and source are credited and subject to any copyright notices concerning any third-party graphics etc. 